\title{
sciendo
}

\section{FOREST DISTURBANCE MAPPING WITH MICROWAVE REMOTE SENSING}

\author{
KAVITA KAUSHIK $^{1}$ AND DEEPAK KUMAR ${ }^{1,2^{*}}$ \\ ${ }^{1}$ Amity Institute of Geoinformatics \& Remote Sensing (AIGIRS), Amity University, Sector \\ 125, Noida - 201303, Gautam Buddha Nagar, Uttar Pradesh, India. \\ https://orcid.org/0000-0003-2863-3152 \\ ${ }^{2}$ International Union for Conservation of Nature (IUCN) Commission Member, Gland, \\ Switzerland. https://orcid.org/0000-0003-4487-7755 \\ *Corresponding author e-mails: dkumar12@amity.edu
}

Received: $2^{\text {nd }}$ March 2020, Accepted: $1^{\text {st }}$ June 2020

\begin{abstract}
It is pre-requisite to conserve and protect the forest cover, therefore mapping of the forest distribution and monitoring of their temporal changes are also necessary. In the field of forestry, radar datasets have a high potential due to its ability to derive/extract information from the surface, sub-surface and even from the depth. The current work tries to utilize the capability of C-band radar datasets provided by Sentinel 1A/B mission to derive the required information for sensing the disturbances in the forest areas. Application of SAR or microwave remote sensing for forest disturbance mapping with dual-polarization is partially developed and have been attempted by limited researchers to process and interpret the derived results. Microwave datasets can map the areas with frequent cloud-cover due to its cloud penetrating capabilities in day-night operation mode. The present work tries to identify and locate the disturbances in forest areas to organize better understanding of detailed information for further analysis with the help of open archive microwave datasets incoherent to optical datasets.
\end{abstract}

Keywords: Forest disturbance, SAR datasets, Mapping, Analysis, Optical Datasets

\section{INTRODUCTION}

Major ecological disturbances may include fires, floods, storms, insect outbreaks etc. and the various devastating effects of human impact on the environment can also be considered major disturbances such as clear-cutting (Margules \& Pressey, 2000), forest clearing and introduction of invasive species. Forests get influenced by climate or by the human activities which lead to different disturbances in the area. Forest fires are a major challenge for the forest managements (Singh et. al., 2017) because they contribute most towards the disturbance as it results in degradation and erosion of the soil, when it spreads in a large area the loss can be higher in terms of infrastructure, lives and the biodiversity. Forests cover are continuously changing. Forest disturbances are the events that cause a change in an ecosystem. Forest disturbances can be both natural and human-induced or some can be functions of both natural and human condition (Mbow et. al., 2014). These disturbances can have different types of effects on different environments as each disturbance affects forest 
differently some can be small scale disturbances or some can have a larger impact on an area. These disturbances affect the forest structure, its composition and the functional processes taking place which shapes the system of the forest.

The current study focuses on disturbances in the forest area due to anthropogenic factors deforestation or the cases of forest fires (Verbesselt et. al., 2010). Deforestation is a major human-induced disturbance. The forest areas are being cleared for various purposes which in turn affects the ecosystem. It can involve the conversion of forest area into the non-forest area which is basically converted into farms, pastures or for urban use. The increasing population in the country is posing a great threat to the forest areas as they are being cleared for buildings or are sold as fuel. The amount of carbon dioxide is increasing in the environment because the areas are cleared in large amounts and not sufficient reforestation is taking place resulting in damaging the habitat and the biodiversity. Deforestation is also a contributor to global warming (Dovì et. al., 2009). Although Forest fires are one important ecological process in an ecosystem as it helps in the regeneration of different species and it positively influences the growth of young trees and even in the dispersal of seeds. On the other hand, Forest fires are major disasters that damage the ecological environment and destroy many forest resources (Sailor \& Dietsch, 2007). The Himalayan forests have been burning regularly during the last few summers when there is no rain for months and the forest become littered with dry leaves and twinges which could burst into flames with the slightest of spark. Forest disturbance mapping is directly detectable by remote sensing data (Wolfgang, 2016). Optical remote sensing data are often hindered by cloud cover and especially when near real-time monitoring is required. Synthetic aperture radar (SAR) is capable to capture deforestation patches and can be used for areas covered with cloud and can provide information day-night due to active remote sensing, in other words (Shahabi \& Hashim, 2015), SAR datasets provide the solutions for a partial set of problems faced by the optical remote sensing.

The current work focuses (a) concepts to understand the forest disturbances, (b) Basic understanding of the microwave image pre-processing methods for forest applications, (c) performing analysis for identification of forest disturbances with dual-polarization microwave datasets, (d) understanding relationship between NDVI and Radar Vegetation Index (RVI) for forest disturbance mapping, and (e) analysis of NDVI to backscatter values in $\mathrm{VH}$ and $\mathrm{VV}$ polarizations.

The potential of radar remote sensing was very high in the field of forestry and has been known for several decades. The advantages of radar data in terms of mapping the cover of vegetation are great as it has many benefits as compared to the optical data as it is easy to obtain information of areas covered with cloud for analyzing frequent changes in any area as it provides time-series data (Shareef et. al., 2016). The SAR data is not affected by the weather conditions; it also provides information on the moisture status along with the structure of a forest area. These strengths were used in a lot of studies on forest mapping and its assessment. Studies on forest resources, ecosystem, contribution and global carbon cycle were largely based on the inputs provided in the form of area and location. Logging activities, cases of fires and storms determines the developing trends in any forest area are essential for operational forest management for ongoing studies related to the changes occurring in the forest area (Smith, 2010). Forest mapping was still lacking behind in development due to limitation with respect to the relatively low temporal and spatial resolution of the available SAR data. The Sentinel 1 data can prove to be a game-changer for forest mapping (Wu \& Pauw, 2008). Sentinel 1 data can prove to be beneficial because it is a very promising remote sensing with the surface, sub-surface or depth information.

In the past, satellite remote sensing was excessively used for mapping forest, many researchers have used the optical data with a moderate resolution for the classification of 
forest types and the classification of forest-based on its density with the help of training sets for processing the supervised classification (Bassuk et al., 2015). The Radar data combined with the optical data can be very much efficient for forest mapping. Different spectral indices have also been used since long back to detect the forest cover. One such spectral index is the NDVI (Normalized differential vegetation index) which is defined as the difference between the NIR and RED reflectance because the forest or vegetation reflects the most in the NIR band and absorbs in the RED band so it was used for mapping and detection (Nutini et. al., 2014). Although it cannot provide exact data so it is only possible to derive broad classifications of the land cover from the data.

There are a variety of disturbances that take place in the forests which are strongly influenced by human activities and climate change. According to the reports of (FAO) food and agriculture organization, there are 78 countries currently participating in the fire effect survey. In it, 60 million hectares of land was reported to be burned per year throughout 4 years from the year 2003 to 2007 (Kimball et. al., 2004). The cases of forest fires whether on a regional level or a global scale are underreported and the disturbances occurring in the forest areas has become a concerning issue for the forest management authorities. A major part of the forest is depleting due to fire, deforestation or due to outbreaks of insects. The disturbances will have their impact on living beings whether in the short term or long term, the event of forest fires can result in infrastructure and life loss, the gases releasing from them in the environment will increase the concentration of dangerous gases which will lead to various health problems and will increase the global warming which will have its impact on human life (Shastri et. al., 2015). The information is needed for the management of forest and dealing with the losses of effects of such phenomena. In the global FRA in 2010, in the report of food and agriculture organization, it was found that southeast Asia countries have the highest rate of deforestation with the total annual loss of forest area of 2.4 Mha in 1990, resulting in forest loss of 29.4 between 1900 and 2010 (Dimov et. al., 2016). In the case of forest cover, it represented a loss of 32 Mha from the year 1990 to 2010. The forest cover was 268 MHA in 1990 and 236 mha in 2010 (Ghosh \& Circle, n.d.).

So far Synthetic aperture radar data in comparison with optical data in the forest disturbance mapping with dual-polarization datasets has not been properly developed yet and even its operational applications have not been realized because the SAR data requires various pre-processing steps. Processing of the SAR data is difficult in comparison to the optical data. The interpretation from the optical data can be easily done and has been used since the 1970s with the help of medium resolution images. The forests of Uttarakhand have been facing different disturbances whether it is due to forest fires or clearing of forest areas for building houses or for commercial purposes. As it is in the Himalayan region various natural calamities also affect its land cover. Climate change has a huge impact on its forest cover. From the past years, there have been regular cases of forest fire in the state in the dry months. The forest cover of the state mostly consists of dry deciduous forest which gets dry during the summers and can catch fire very easily, it is not easy to detect the forest fires as they are not easily detectable unless it has consumed a large area, the ground fires are hard to spot. The forest of Uttarakhand is also facing the problem of over-extraction and live-stock gazing. The forest cover in the state is decreased $268 \mathrm{sq} \mathrm{km}$ in between the course of two years. The maximum forest cover was lost in the Uttarkashi district which recorded a loss of 73 sq. km, other districts were the forest cover loss was alarming were Nainital, Haridwar, Udham Singh Nagar and Bagheshwar with the loss of 70 sq. km, 27 sq. km, 40 sq. km and 22 sq. $\mathrm{km}$ respectively.

A study by Prabhakar et al. (2006) in the Almora district of Uttrakhand estimated that a large amount of forest area was degraded which was approximately $78 \%$ and had a crown 
cover of less than $40 \%$ all because of the development activities taking place in the district. With increasing cases of disturbance in the forest areas, there are resulting increase of the species loss. When any forest cover faces species loss there are increased chances of invasion of different species which as a result create a competitive impact on the existing species. According to Prabhakar et al. (2006) in the forest cover in Uttarakhand disturbances in the forest structure and composition creates possibilities of invasion of species such as Lantana Camara, Parthenium, Eupatorium and Ageratum spp.

The regeneration of important forest species and vegetation growth are directly or indirectly is affected by the abrupt changes in the climatic conditions of Uttarakhand. As stated in Negi et al. 2012 various factors are leading towards extinctions of wild flora and fauna e.g. rise in temperature, the rapid increase in deforestation, forest destruction for habitat, decrease in water resources and changes in vegetation.

\section{MATERIALS AND METHODS}

\section{Study Area}

The study was conducted on NAINITAL district of Uttarakhand state in India. It lies between $29^{\circ} 0^{\prime}$ and $29^{\circ} 36^{\prime} 21^{\prime \prime} \mathrm{N}$ latitudes and $78^{\circ} 50^{\prime} 53^{\prime \prime}$ and $80^{\circ} 0^{\prime} \mathrm{E}$ longitudes.

Table 1: Details of the development blocks and tehsils in Nainital District

\begin{tabular}{|c|c|c|c|c|c|}
\hline S. No & NAME BLOCK & AREA (in $\mathbf{~ k m}^{\mathbf{2}}$ ) & $\begin{array}{c}\text { NAME OF } \\
\text { TEHSIL }\end{array}$ & $\begin{array}{c}\text { NO. OF } \\
\text { VILLAGES }\end{array}$ & $\begin{array}{c}\text { NO. OF } \\
\text { TOWNS }\end{array}$ \\
\hline $\mathbf{1 .}$ & Haldwani & 217.20 & Haldwani & 252 & 1 \\
\hline $\mathbf{2 .}$ & Ramnagar & 209.22 & Haldwani & 187 & 1 \\
\hline $\mathbf{3 .}$ & Kotabagh & 174.92 & Nainital & 115 & 1 \\
\hline $\mathbf{4 .}$ & Dhari & 238.69 & Dhari & 46 & 1 \\
\hline $\mathbf{5 .}$ & Okhalkanda & 294.96 & Dhari & 107 & 1 \\
\hline $\mathbf{6 .}$ & Ramgarh & 276.61 & Kosya/ kutoli & 130 & 1 \\
\hline $\mathbf{7 .}$ & Betalghat & 256.33 & Nainital & 133 & 1 \\
\hline $\mathbf{8 .}$ & Bhimtal & 200.52 & Nainital & 112 & 1 \\
\hline
\end{tabular}

There are 8 developmental blocks and four tehsils. Nainital, Haldwani, Dhari and Kosya Kutoliand are the four tehsils of the district. Ramnagar, Haldwani, Ramgarh, Bhimtal, Dhari, Kotabagh, Okhalkanda and Betalghat are the eight development blocks. As per the census of 2001 the total population of the district was recorded to be 7, 62,909 and its total area/ geographical area was $4064.33 \mathrm{sq}$. km. The density of population in Nainital is 198 persons per sq. km. The summary of developmental blocks is summarized in table 1 . 
Fig. 1: Location of the Study Area

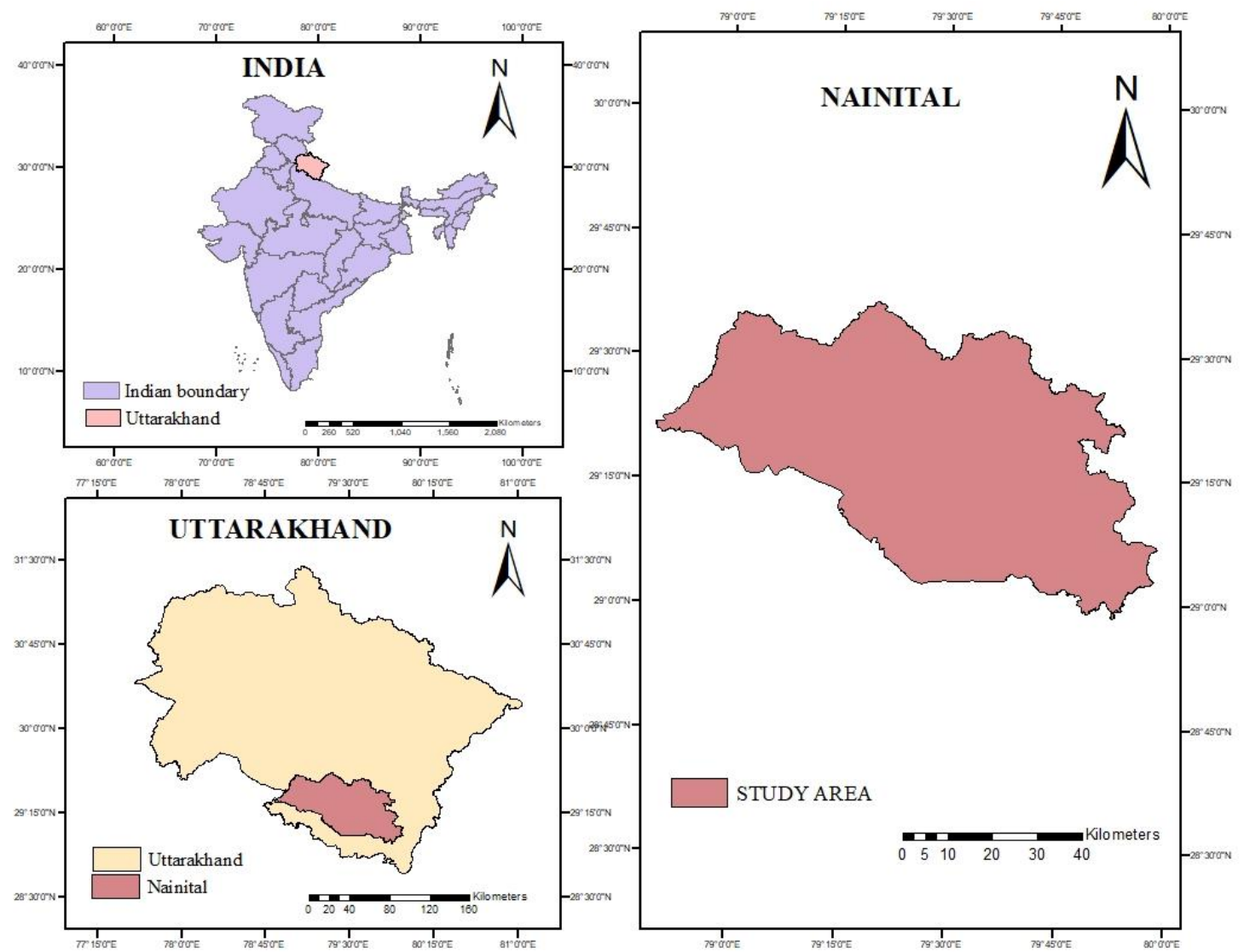

Administrative Setup

The district has eight tehsils Kosyakutauli, Nainital, Dhari, Betalghat, Ramnagar, Kaladhungi, Haldwani and Lalkuan. In the Nainital district law and order has control over all the works and activities of district administration and also has control over other government departments and also monitors the development works. District magistrate is the overall head of the district, for different administrative works the magistrate is supported by different teams for example; SSP for law and order, CDO for development works, SDMs for the work related to forests. Figure 1 shows the extend of and location of the study area.

\section{Climate and Rainfall}

Nainital enjoys a pleasant climate throughout the year, as the temperature is influenced by the Himalayan ranges. The temperature varies according to the location as in the hilly areas the max temperature rarely exceeds $25^{\circ} \mathrm{C}$ although in the plain areas the max temperature goes up to $46^{\circ} \mathrm{C}$ and the minimum temperature falls to $1^{\circ} \mathrm{C}$ in the plain areas, in the case of hilly areas the minimum temperature falls below $0.9^{\circ} \mathrm{C}$ during winters. The district experiences moderate to heavy rainfalls during the monsoon season. The annual rainfall 
Kaushik K., Kumar D.: Forest Disturbance Mapping With Microwave Remote Sensing

varies from $1200 \mathrm{~mm}$ to $2647 \mathrm{~mm}$ and average annual rainfall is $1246 \mathrm{~mm}$. Table 2 summarizes the weather condition of Nainital district monthly.

Table 2: Summary of weather condition at Nainital (month-wise average)

\begin{tabular}{|c|c|c|c|c|c|c|c|c|c|c|c|c|}
\hline & $\underset{\Xi}{\Xi}$ & 过 & $\sum^{\bar{\pi}}$ & 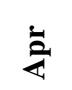 & $\sum^{\mathrm{J}}$ & $\stackrel{\mathscr{\Xi}}{\Xi}$ & 光 & $\sum^{\infty 00}$ & हैँ & $\bar{\Xi}$ & ż & 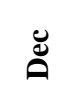 \\
\hline Avg. Temp $\left({ }^{0} \mathrm{C}\right)$ & 5.2 & 6.8 & 10.6 & 15 & 18.2 & 18.6 & 17.2 & 16.8 & 15.9 & 13.6 & 10.6 & 7.8 \\
\hline Min. Temp. $\left({ }^{0} \mathrm{C}\right)$ & 1.1 & 2.4 & 5.7 & 10.1 & 13.3 & 14.4 & 14.3 & 14 & 12.6 & 9.3 & 5.9 & 3.2 \\
\hline Max. temp. $\left({ }^{0} \mathrm{C}\right)$ & 9.4 & 11.2 & 15.5 & 19.9 & 23.2 & 22.6 & 20.1 & 19.6 & 19.3 & 18 & 15.4 & 12.4 \\
\hline Avg. Temp $\left({ }^{0} \mathrm{C}\right)$ & 41.4 & 44.2 & 51.1 & 59.0 & 64.8 & 65.5 & 63.0 & 62.2 & 60.6 & 56.5 & 51.1 & 46.0 \\
\hline Min. Temp. $\left({ }^{0} \mathrm{C}\right)$ & 34.0 & 36.3 & 42.3 & 50.2 & 55.9 & 57.9 & 57.7 & 57.2 & 54.7 & 48.7 & 42.6 & 37.8 \\
\hline Max. Temp. $\left({ }^{0} \mathrm{C}\right)$ & 48.9 & 52.2 & 59.9 & 67.8 & 73.8 & 73.2 & 68.2 & 67.3 & 66.7 & 64.4 & 59.7 & 54.3 \\
\hline $\begin{array}{l}\text { Precipitation } \\
(\mathrm{nm})\end{array}$ & 64 & 56 & 60 & 35 & 67 & 178 & 443 & 381 & 241 & 76 & 8 & 27 \\
\hline
\end{tabular}

\section{Physiography}

There are three broad physiographic divisions in Nainital district viz., the lesser Himalayan zone, the Himalayan foothill zone, the piedmont alluvial tract corresponding to the sub-divisions of Himalayas.

Lesser Himalaya: The lesser Himalayan zone comprises of distinct terraces and also deep valleys, these valleys in this zone are of alluvial as well as glacial origin. The terraces are rugged with a sudden rise or fall in the slope. It has a max elevation of $2610 \mathrm{~m}$ above sea level. This zone is filled up by fluvial terrace deposits. North-North-west - South-South-east are the regional trends of the major ridges found in this region.

The Himalayan Foothill Zone: This zone has the max elevation of $1677 \mathrm{~m}$ above mean sea level. It runs in the North-West - South-East direction. In the Zone of Himalayan foothills, the slope is moderate and even has flat-topped hills. Due to the structural discontinuities, the siwaliks is truncated towards the south.

Piedmont Alluvial Zone: The streams running downhill from the upper Himalayas deposits sediments at the Himalayan foothills which results in an extensive zone of recent sediments. The recent sediments are classifying as Tarai and Bhabar. These zones move along the Himalayan foothill zone and extend in the Northwest-Southeast direction. These zones are separated by spring line. The slope becomes flat beyond the spring line, it decreases towards the south. The gradient in this zone from Northwest- Southwest varies from 9.5 to $17 \mathrm{~m} / \mathrm{km}$. The soils are a natural, dynamic, heterogeneous, non-renewable resource, which supports plant and animal life. Lesser Himalaya and Siwaliks which are of decreasing height possess very little levelled land. Under the moist and cool climate of the district, the soils have been developed from a different type of rocks such as schist, gneiss, granite, limestone, shales, slate and stone etc. 


\section{Soil}

Very steep to steep hills and Glacio-fluvial valleys are dominantly occupied by very shallow to moderately shallow excessively drained, sandy-skeletal to loamy skeletal, neutral to slightly acidic with low available water capacity soils. They have been classified as Lithic/Typic Cryorthents. All these soils are not suitable for agriculture practices and are generally occupied with sparse vegetation. The major part of the lesser Himalayan zone is under forest and it is highly composed of altered and compressed rocks such as granites and quartzite. Different types of cultivation can be seen in the district as terrace cultivation is practised on fairly steep hills slope. Low lying wet and dry cultivation are found on the uplands. The Valley slopes in the district dominantly are deep, loamy, well-drained and a little acidic.

\section{Satellite Data Acquisition}

The image of the study area for the base layer was acquired from USGS Earth Explorer (https://earthexplorer.usgs.gov/). The SAR images were acquired by the European space agency and Alaska satellite facility. Sentinel 1A/B and Sentinel 2A/B images were used for making the land use land cover map for identification of the disturbances occurring in the forest area. The European Space Agency with the constellation of two satellites namely Sentinel 1A and Sentinel 1B are concluded in the mission by ESA are capable to provide $\mathrm{C}$-band synthetic-aperture radar datasets. The C-band has the spatial resolution of $5 \mathrm{~m}$ and a swath of up to $400 \mathrm{~km}$. The constellations of these two satellites are on a sun-synchronous, near-polar $\left(98.18^{\circ}\right)$ orbit. This orbit has a repeat cycle of 12-day and per cycle, it completes 175 orbits. The details of typical bands are summarized as:

$$
\begin{aligned}
& \text { P-band }=65 \mathrm{~cm}, \text { L-band }=23 \mathrm{~cm} \\
& \text { S-band }=10 \mathrm{~cm}, \mathbf{C} \text {-band }=5 \mathrm{~cm} \\
& \text { X-band }=3 \mathrm{~cm}, \mathbf{K} \text {-band }=1.2 \mathrm{~cm}
\end{aligned}
$$

The current work utilized datasets with the following specifications:

$$
\begin{aligned}
& \text { Product type }=\text { GRD (Ground range detection). } \\
& \text { Mission= Sentinel 1A } \\
& \text { Acquisition mode }=\text { IW (interferometric wide) } \\
& \text { Polarizations }=\text { VH and VV }
\end{aligned}
$$

In the European Copernicus programme, Sentinel-2A/B satellite was the first optical Earth observation satellite. Sentinel 2A was built by Airbus Defense and Space to provide a multispectral instrument with unique image quality. Sentinel-2A/B satellite has 13 spectral bands, from visible and the near-infrared to the shortwave infrared. The bands have different spatial resolutions ranging from 10 to 60 meters on the ground to help global land monitoring to an exceptional level. Table 3 summarizes the spectral and spatial information of Sentinel 2A/B datasets. 
Kaushik K., Kumar D.: Forest Disturbance Mapping With Microwave Remote Sensing

Table 3: Summary of Sentinel 2A/B band specifications Images

\begin{tabular}{|l|c|c|}
\hline \multicolumn{1}{|c|}{ Sentinel-2 Bands } & Central Wavelength & Resolution \\
\hline BAND 1- Coastal aerosols & 0.443 & 60 \\
\hline BAND 2- Blue & 0.490 & 10 \\
\hline BAND 3- Green & 0.560 & 10 \\
\hline BAND 4-RED & 0.665 & 10 \\
\hline BAND 5- Vegetation red edge & 0.705 & 20 \\
\hline BAND 6- Vegetation red edge & 0.740 & 20 \\
\hline BAND 7- Vegetation red edge & 0.783 & 20 \\
\hline BAND 8- NIR & 0.842 & 10 \\
\hline BAND 8A- Vegetation red edge & 0.865 & 20 \\
\hline BAND 9- Water vapour & 0.945 & 60 \\
\hline BAND 10- SWIR- cirrus & 1.375 & 60 \\
\hline BAND 11- SWIR & 1.610 & 20 \\
\hline BAND 12- SWIR & 2.190 & 20 \\
\hline
\end{tabular}

Table 4: Summary of Sentinel 2A/B satellite parameters and acquisition

\begin{tabular}{|l|l|}
\hline Sentinel- 2A launch & June 2015, by Vega from Kourou, French Guiana \\
\hline Sentinel- 2B launch & June 2016, by Rockot from Plesetsk, Russia. \\
\hline Orbit & Sun-synchronous. \\
\hline Revisit time & Five days \\
\hline Altitude & $786 \mathrm{~km}$ \\
\hline Swath & $290 \mathrm{~km}$ \\
\hline Sensor & MSI (multispectral imager) \\
\hline Bands & 13 \\
\hline
\end{tabular}

Table 4 summarizes the satellite parameters of Sentinel 2A/B satellite along with acquisition date.

\section{Software Used}

The current research work uses ERDAS, ArcGIS and SNAP software. For performing processing of radar images, SNAP software was used (which is freely available online on the site (https://step.esa.int/main/download/snap-download/)). Also, SNAP software has many features like Portability, Extensibility, Memory management, the platform of modular rich client, an abstraction of generic EO data and graph processing framework that makes the architecture of the software ideal for processes and analysis regarding earth observations. For the processing of the optical (Sentinel-2) images and for making the NDVI (Normalized differential vegetation index) ERDAS software was used. Erdas Imagine is an image processing software and it allows processing with satellite imagery along with vector data. Erdas is capable to handle the hyperspectral data. ArcGIS was used for extracting the values which were then used for correlating the values of NDVI and RVI image and for the analysis of backscatter values and the NDVI values together. The ArcGIS also provides various levels of functionality for all interface. 


\section{Methods and Methodology}

Land Use Land Cover Map

Land use land cover map of NAINITAL provides a brief introduction of the study area it was processed to find out the forest type of the region for further analysis in terms of SAR data utilization in forest studies. Figure 2 illustrates the brief methodology for sentinel $2 \mathrm{~A} / \mathrm{B}$ landuse-landcover classification methods.

\section{Fig. 2: Methodology for Land Use Land Cover Classification from Sentinel 2A/B} datasets

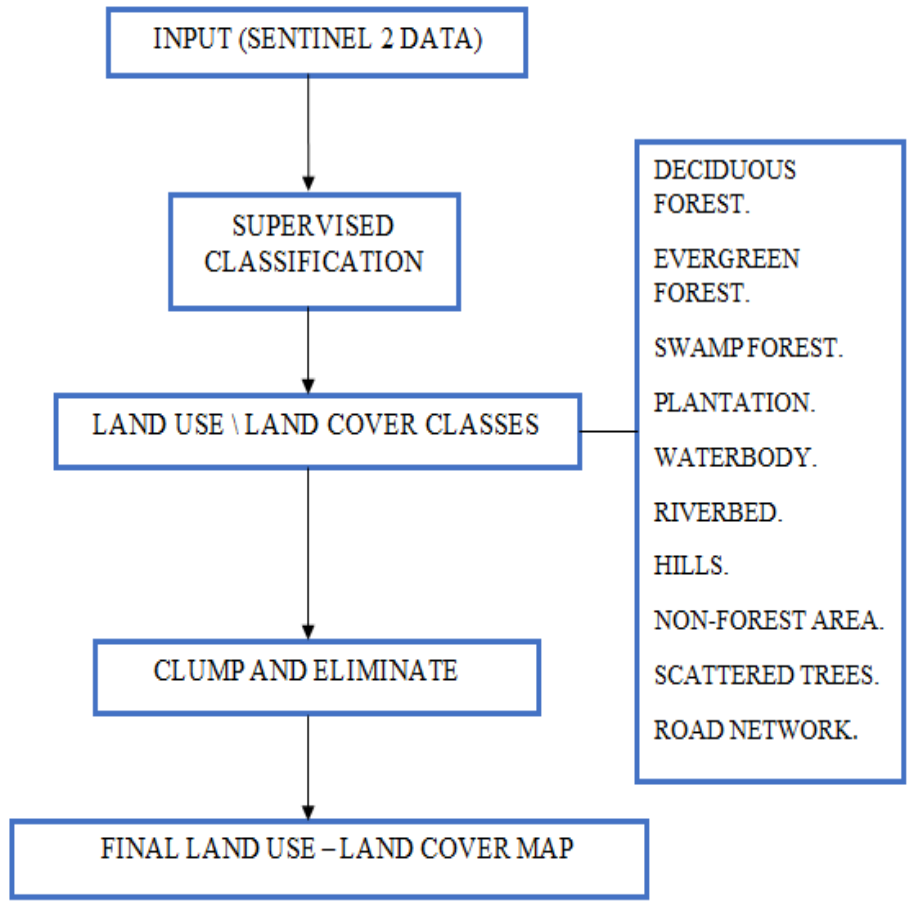

\section{Pre-Processing of Radar Datasets}

The preprocessing workflow for Sentinel-1 level 1 GRD data is being shown in figure 3. In the general annotation of the products, the terrain height is provided which is constant in terms of range but varies in azimuth and is used to correct the ellipsoid projection of the GRD products. Therefore, with the help of Earth ellipsoid model the SAR GRD data were projected to ground range and the products acquired by the GRD data provided focused SAR data.

As Sentinel 1 mission provides data form dual-polarization from C-band synthetic aperture radar instrument. This work utilizes a dual-band cross-polarization $(\mathrm{VV}+\mathrm{VH})$ mode. The various preprocessing steps for the SAR GRD data includes calibration, multi looking, Range-Doppler terrain correction and single product speckle filter. 


\section{Fig. 3: Brief methodology for Sentinel 1 A/B GRD data Processing}

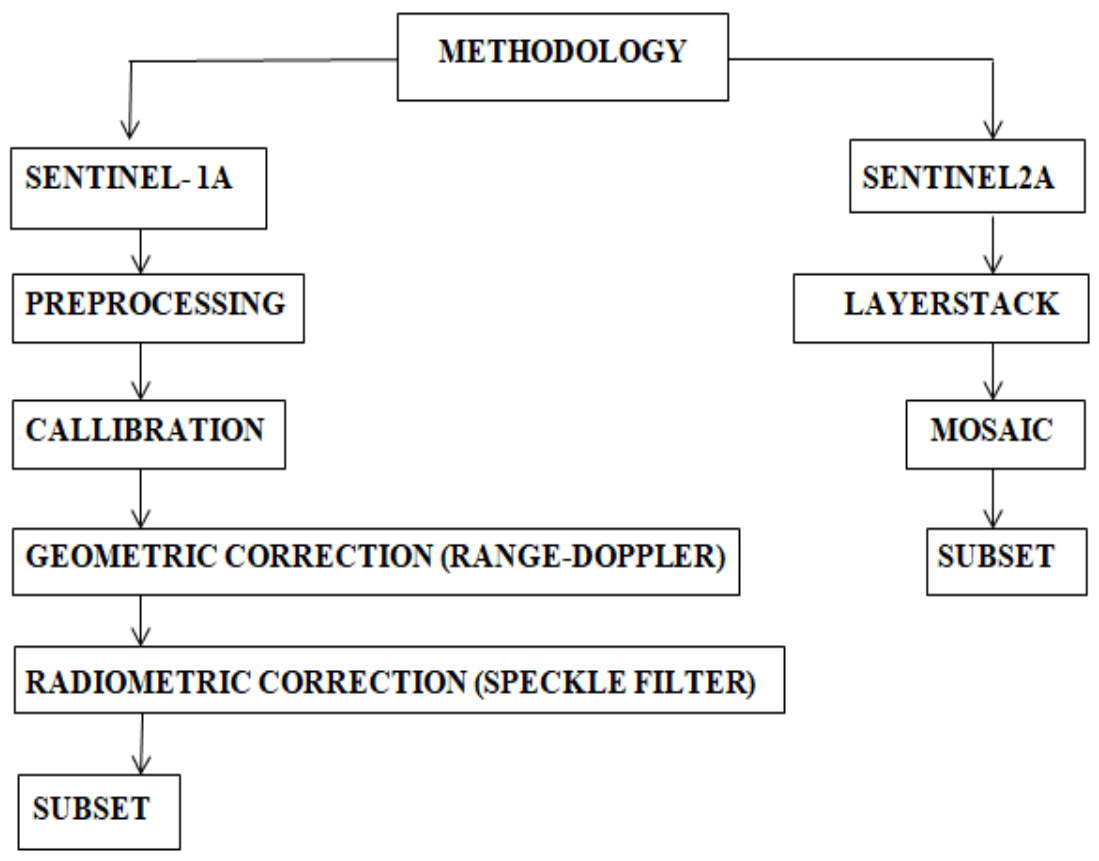

a) Calibration: Sentinel-1 Level-1 product is not radiometrically corrected by default. However, for using the Synthetic aperture radar the radar reflectivity (stored as DN within Sentinel-1 products) has to be converted to it's physical units to provide radar backscatter values with the process of radiometric calibration.

b) Multi-look: Multi-looking helps to mitigate the speckle present in the image for a better interpretation of the image. It means that the radar beam is divided into sub-beams which results in the introduction of speckle in the image but summing up these subs -beams together will reduce the amount of error in the image in the form of speckle and will help in better interpretation of the image.

c) Geometric correction: The geometric correction of the input data is performed by using the "Range Doppler Terrain Correction" method and is implemented through SNAP's S1TBX software. Data from the Shuttle Radar Topography Mission (SRTM) with a resolution of a 1-arc second (30 meters) are used for the geometric correction.

d) Speckle filter: Speckle present in the radar image makes it difficult to interpret the image, as there may be chances of wrong information due to slight variations in it. It will be difficult to identify the feature, hence speckle filter is used to accurately derive the output.

Data Analysis

Figure 4 visualizes the detailed methodology for data analysis. It provides the synoptic view of the complete framework for comprehensive data analysis. 
Fig. 4: Methodology for Data Analysis

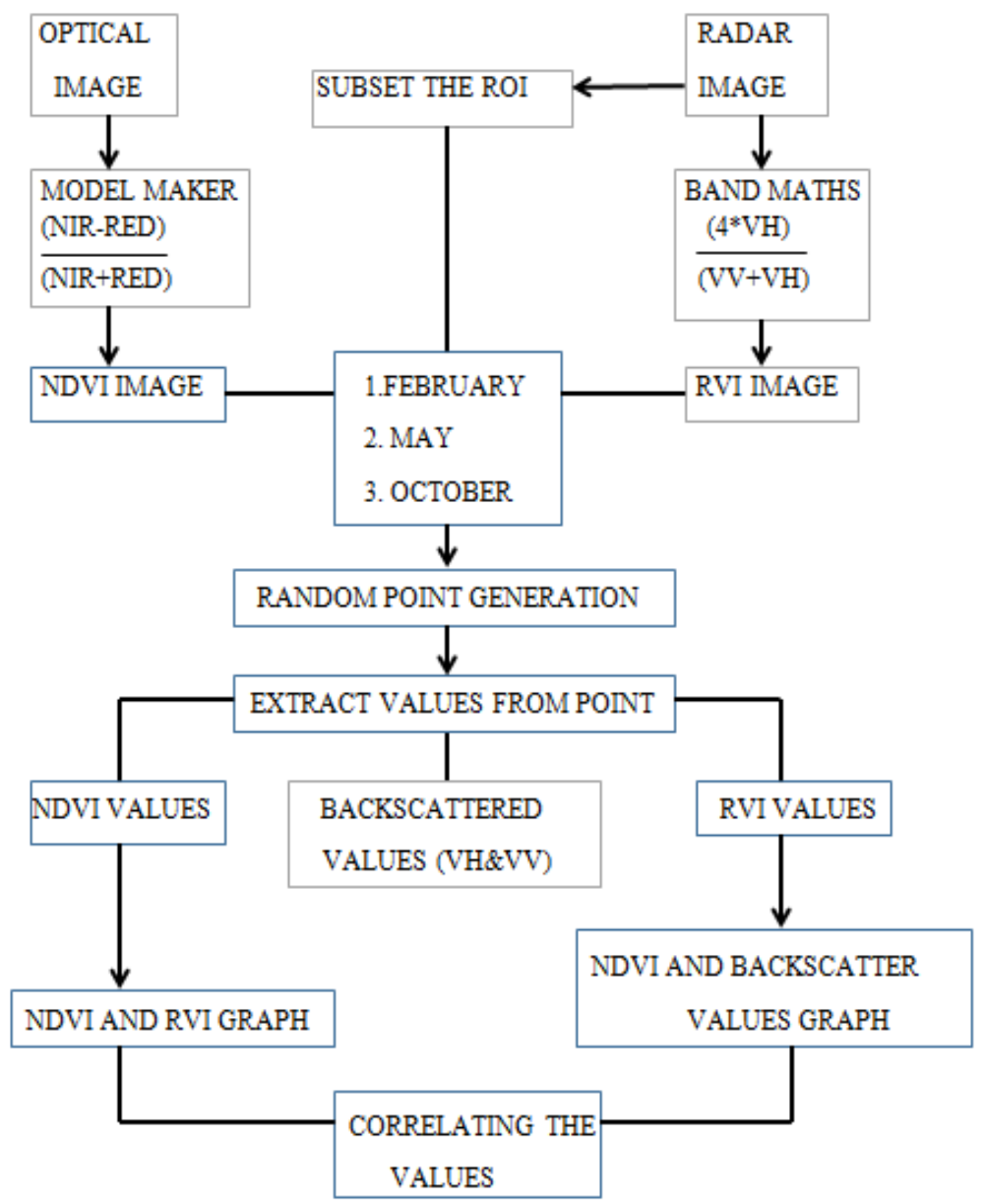




\section{RESULTS AND ANALYSIS}

\section{Land use-Land-Cover Map from Sentinel 2A/B}

Fig. 5: Land Use Land Cover Map of Nainital

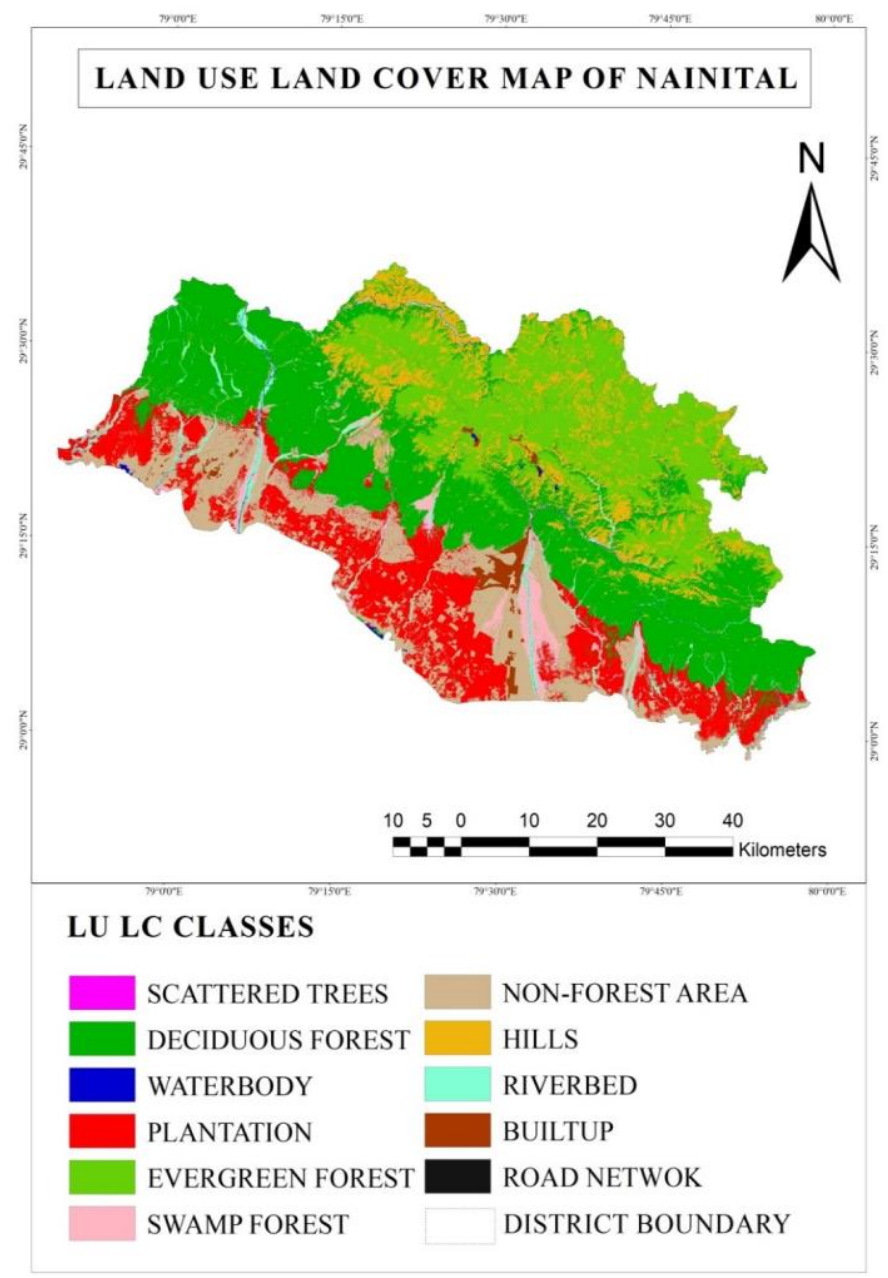

\section{SAR data processing}

Radar-based SAR images were used to know their potential in the study of Seasonal Forest disturbance mapping. Radar images record backscattered values as different features have different backscatter values. The range for the forest cover is between $-\mathrm{o}$ to $-10 \mathrm{db}$. Although the backscatter values get influenced by moisture content and soil parameters. The radar images were preprocessed before being used for analysis as they are geometrically and radiometrically corrected for better interpretation. The Radar images of three months (FEBRUARY, MAY AND OCTOBER) were used analyse the disturbance in the forest areas. The Sentinel 1A raw images for all three months with $\mathrm{VH}$ and $\mathrm{VV}$ polarizations are being shown in figure 6 . 
Fig. 6: Sentinel 1 Raw Images in dual-polarizations

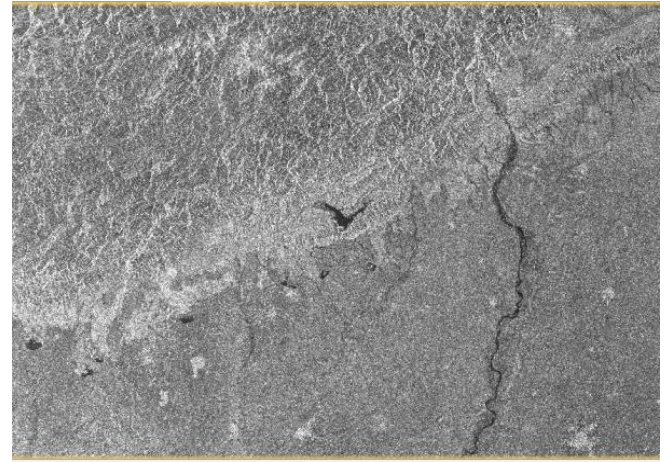

a) VH Polarization -February

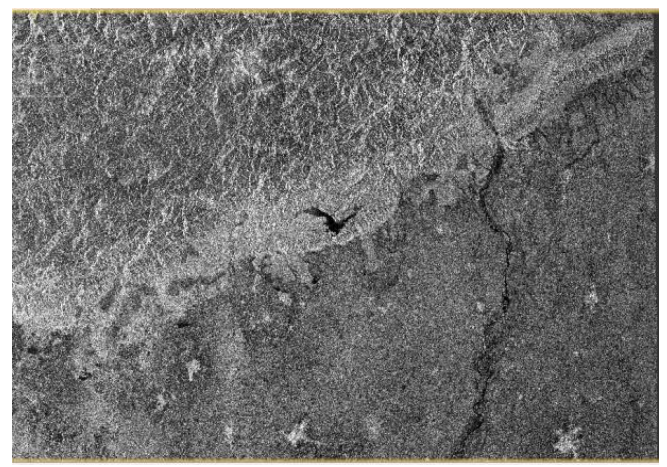

a) VH Polarization-May

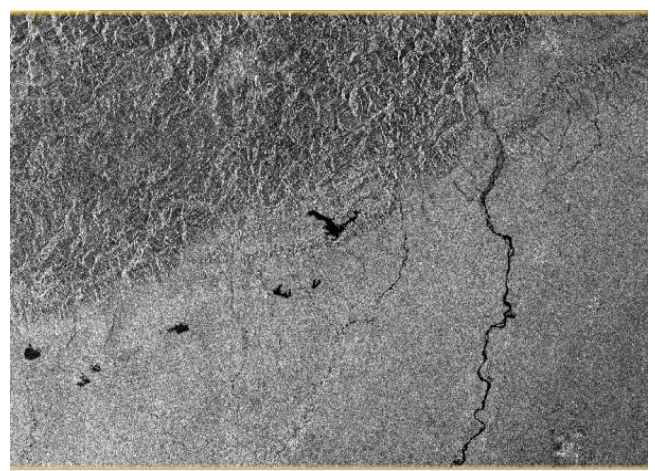

a) VH Polarization-October

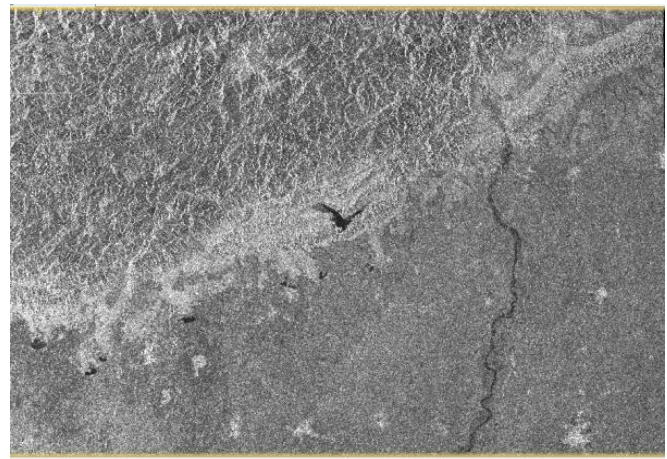

b) VV Polarization-February

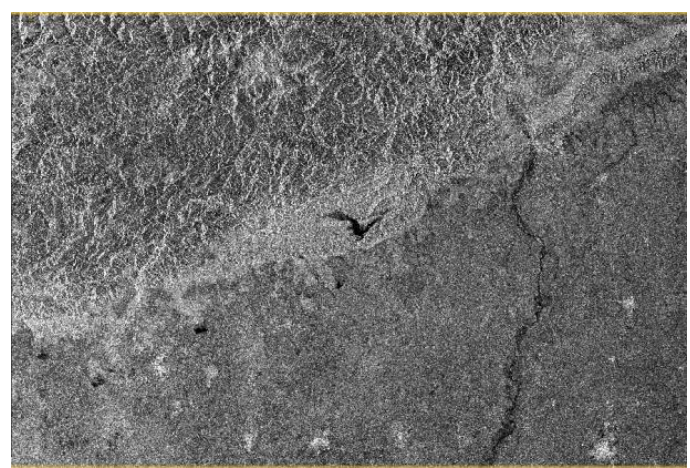

b) VV Polarization-May

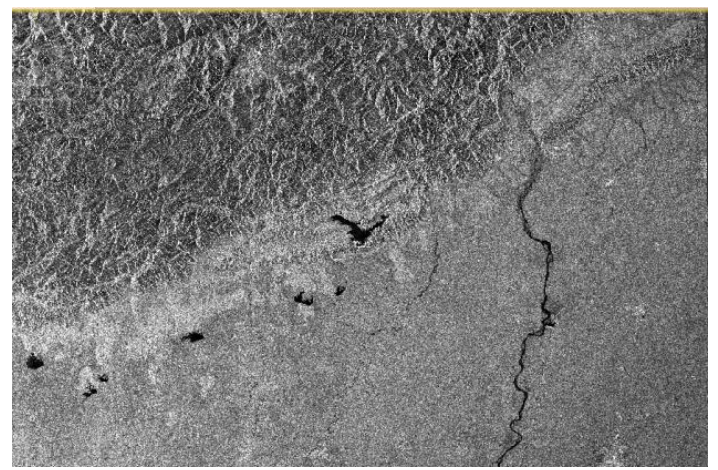

b) VV Polarization-October

CALIBRATION: The First step of preprocessing of the sentinel 1 image is to apply radiometric calibration, which is used to convert the data from digital numbers to decibels. The products acquired from Sentinel-1 Level-1 are not corrected by default radiometrically. In order to utilize the synthetic aperture radar, the radar echoes (stored as DN within Sentinel-1 products) has to be changed into physical units to provide radar backscatter values through the process of radiometric calibration. A comparative study of SAR images was obtained from different sensors or even from the same sensor for different acquisition dates 
or acquisition modes is not possible without radiometric correction of the image. It is performed through the SNAP software. We can observe the variations between the decibels and digital number.

INPUT: SAR GRD raw image (Sentinel 1A image),

OUTPUT: Sigma nought calibrated radar backscattered image.

Fig. 7: Sigma nought calibrated radar backscatter image

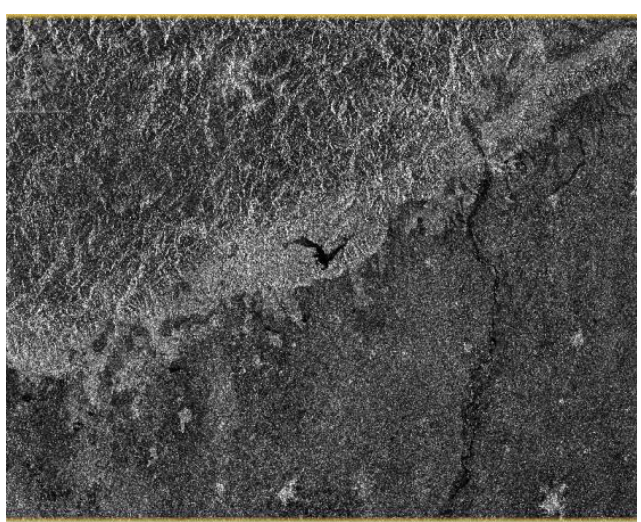

a) VH Polarization

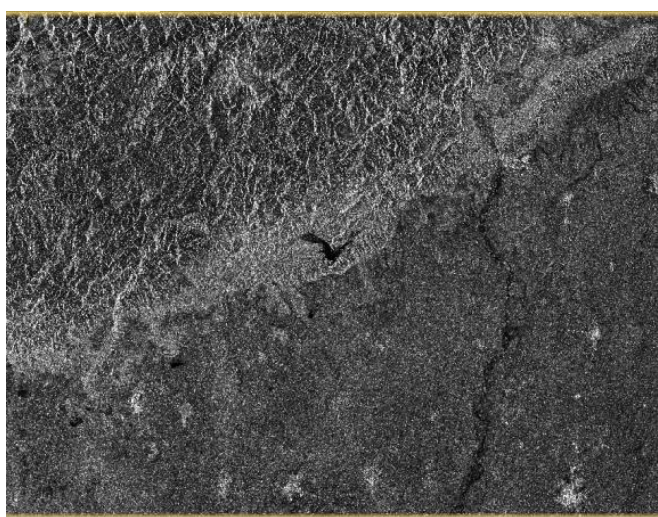

b) VV Polarization

MULTILOOKING: Multilooking was used to mitigate the speckle present in the image for a better interpretation of the image.

INPUT: The Sigma nought calibrated radar backscattered image (figure 7).

OUTPUT: Multi look image.

Fig. 8: Multi look Sigma nought calibrated radar backscatter image

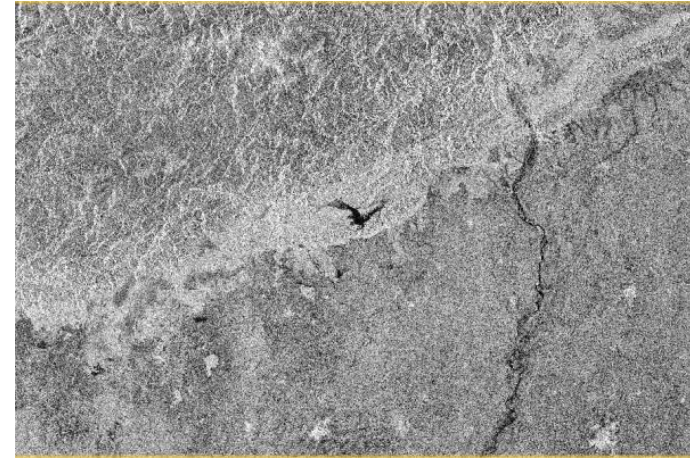

a) VH Polarization

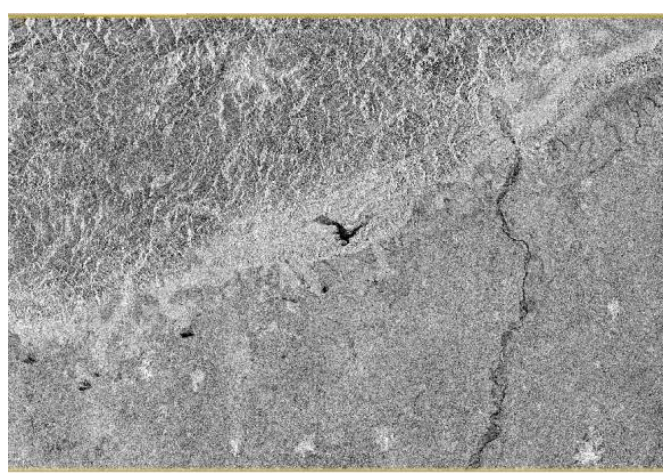

b) VV Polarization

GEOMETRIC CORRECTION: The geometric correction of the input data was done through the "Range Doppler Terrain Correction". Data from the Shuttle Radar Topography Mission (SRTM) with a resolution of a 1-arc second (30 meters) to convert the image into map coordinate system. It was processed through terrain correction (Range Doppler terrain correction)

INPUT: Multi look sigma nought calibrated radar backscatter image (figure 8) and DEM was automatically downloaded from SRTM data archive through SNAP. 
OUTPUT: Geometrically corrected sigma nought radar backscattered images.

Fig. 9: Geometrically corrected sigma nought radar backscattered images

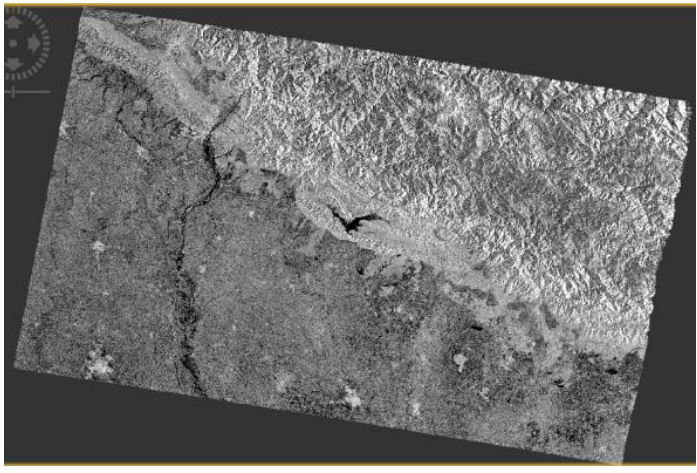

a) VH Polarization

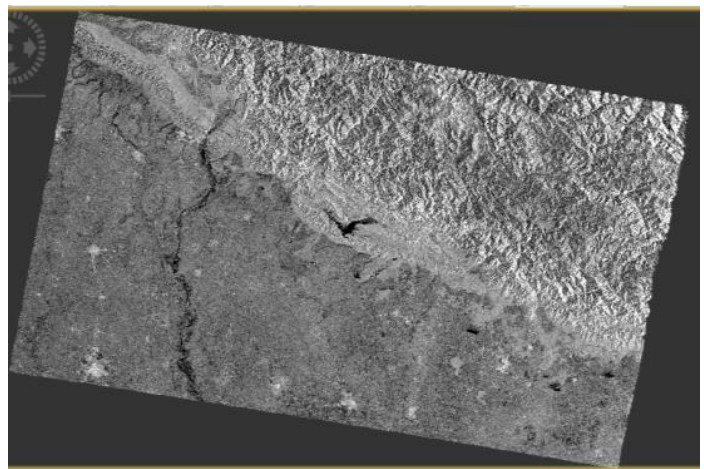

b) VV Polarization

Fig. 10: Derived products during range-Doppler terrain correction radar backscattered images

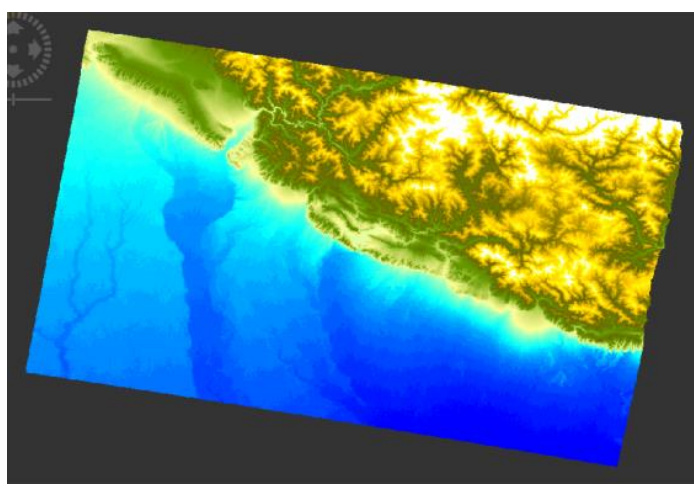

a) Derived DEM

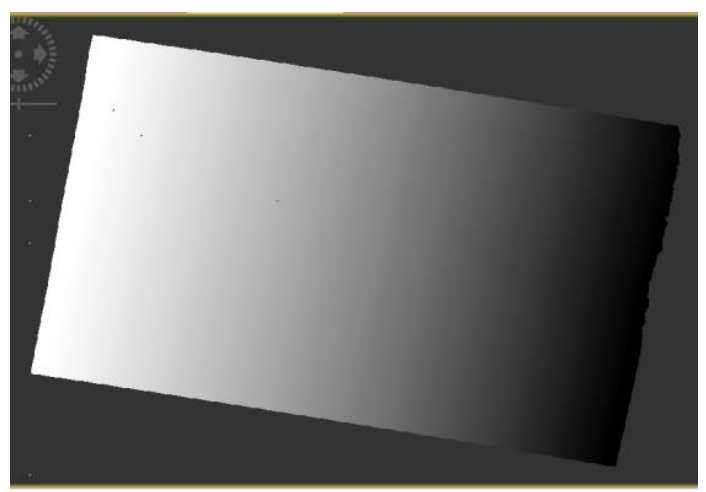

b) Incidence angle from an ellipsoid

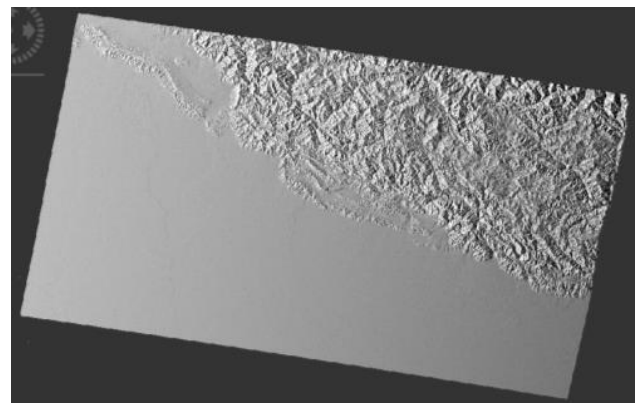

c) Projected local incidence angle.

SPECKLE FILTERING: Speckle filter was used to remove the noisy appearance of a homogenous area of the scene. For applying to filter we are using single product *technique with lee sigma type filter. 
Kaushik K., Kumar D.: Forest Disturbance Mapping With Microwave Remote Sensing

INPUT: Geometrically corrected sigma nought radar backscattered images (figure 9).

OUTPUT: Radiometrically and geometrically corrected sigma nought radar backscattered images with reduced speckle effect

Fig. 11: Geometrically and radiometrically corrected sigma nought radar backscattered images

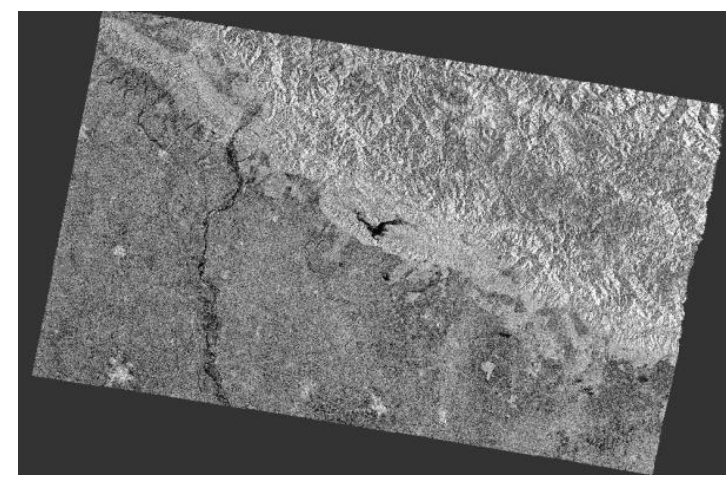

a) VH Polarization

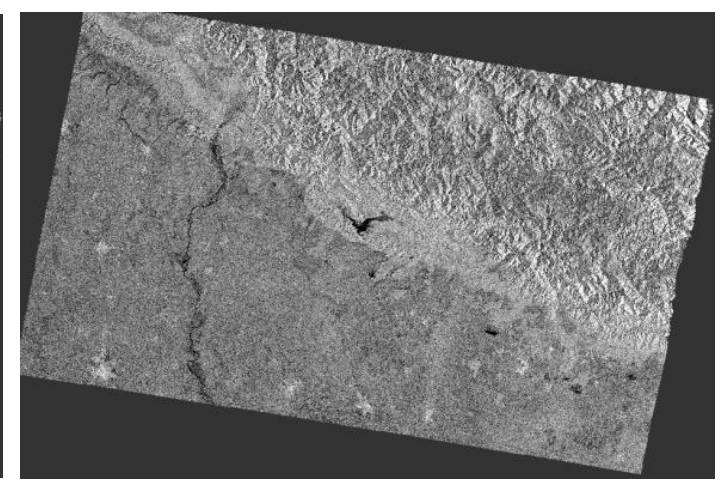

b) VV Polarization

SUBSET: The subset was carried out geometrically and radiometrically corrected sigma nought radar backscattered images for the extraction of the study area.

INPUT: The radiometrically and geometrically corrected image was used as the input. The vector shapefile of the study area was used to subset the image.

Fig. 12: Corrected image with overlaid vector shapefile

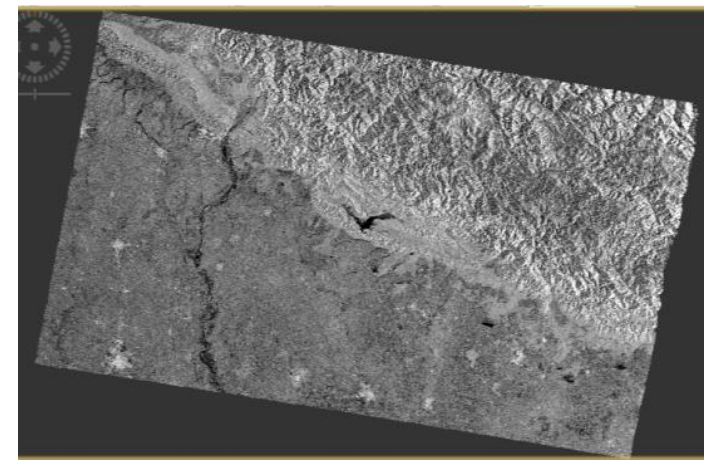

a) Full Scene

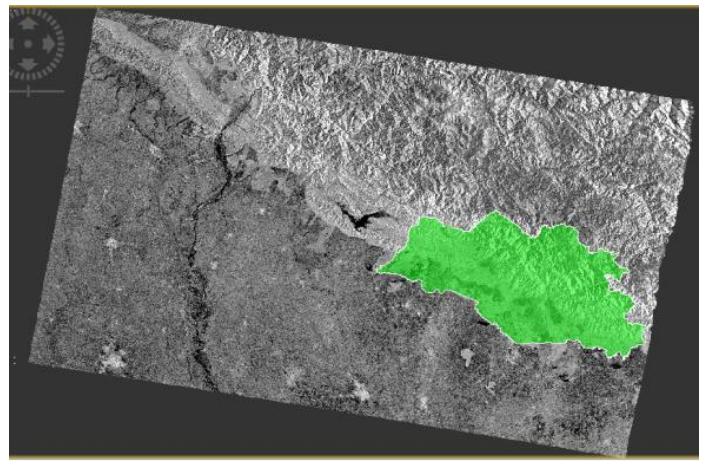

b) Full Scene with vector file 


\section{OUTPUT:}

Fig. 13: Subset image of the study area in dual-polarization

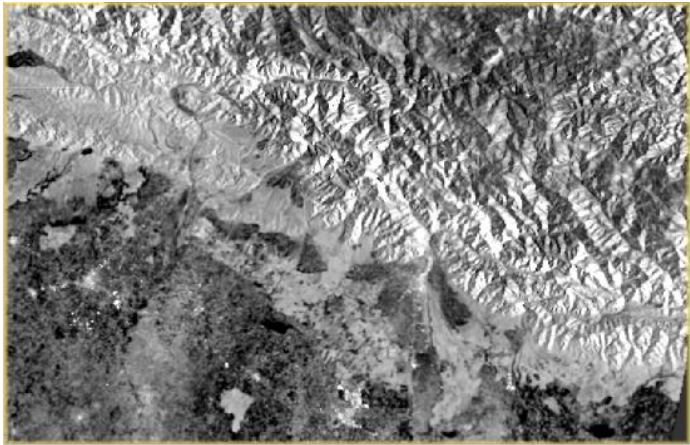

a) VH Polarization

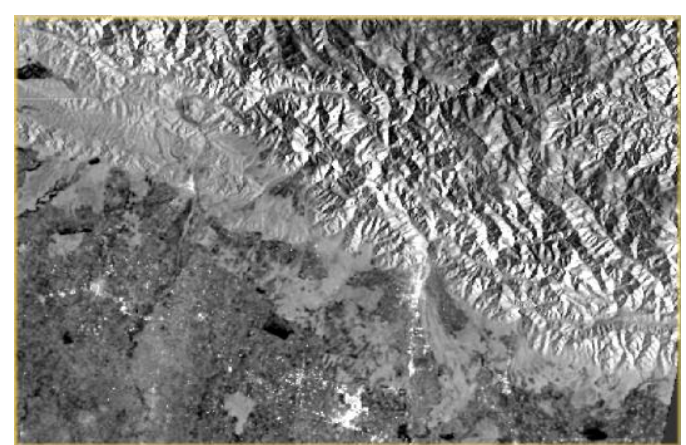

b) VV Polarization

False Color Composition (FCC) of SAR Images

After a subset of the study area, the false-colour composite of the image was created for better interpretation of the region of interest. The image is created using the ratio of $\mathrm{VV}$ and $\mathrm{VH}$ polarization. The FCC images visualize the feature in an easier way to understand the features as it can be noticed that the water body is depicted in black colour. The settlement in the image is shown with the bright white colour in the study area. The location of the study area (Nainital) lies in the Himalayas, due to this reason there are not the prominent presence of settlement patterns. The shades of green in the image represents the forest cover of the area. Figure 14 shows the image for the month of May, so it is even visible that the areas with shredded leaves exhibit varying colour.

Fig. 14: False Color Composition (FCC) of the study area

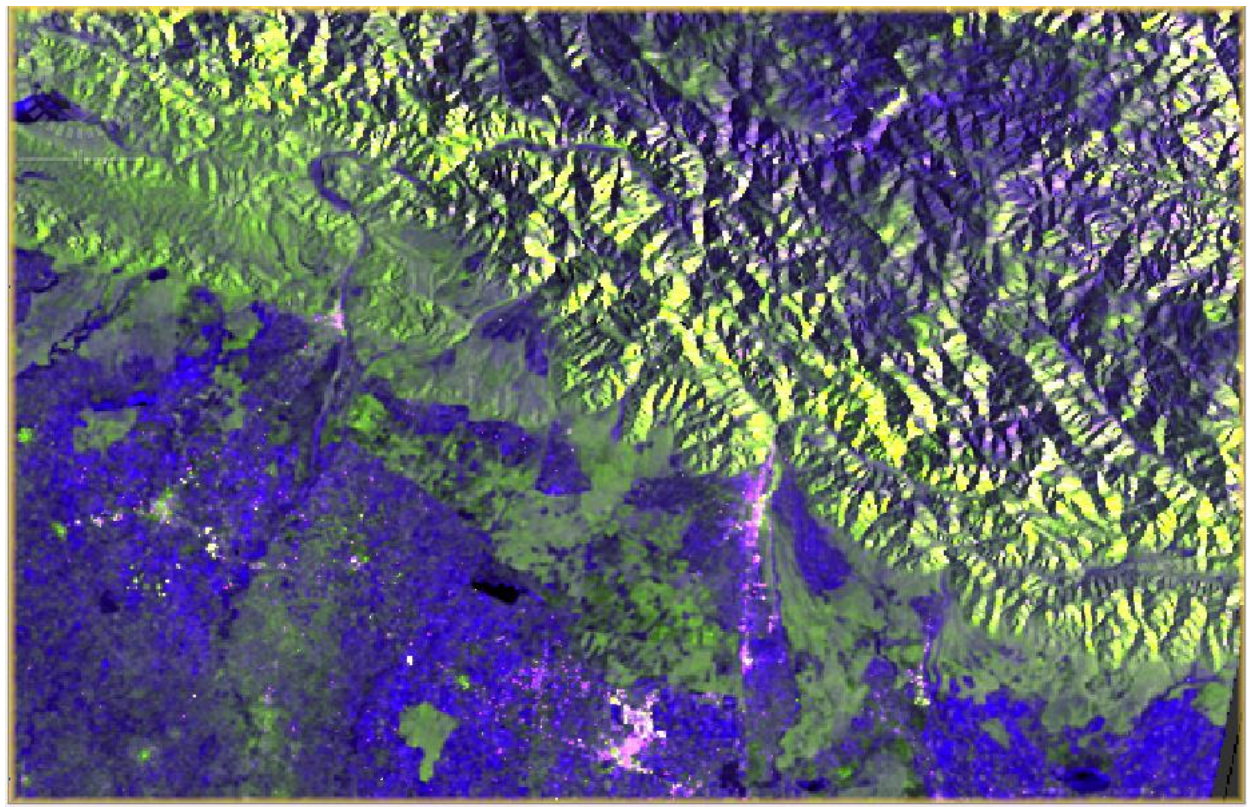


Kaushik K., Kumar D.: Forest Disturbance Mapping With Microwave Remote Sensing

\section{NDVI AND RVI Image Generation}

NDVI typically refers to normalized differential vegetation index and in forestry, it is used to quantify forest supply and leaf area index. NDVI is a standardized way of measuring healthy vegetation. It is measured as the difference between NIR and red band. A higher NDVI value represents dense vegetation and a value close to 0 can be an urban area while the value in negative will represents a water body. The range of NDVI is from -1 to +1 . RVI is widely used for vegetation cover mapping.

Fig. 15: FCC Images with corresponding NDVI images

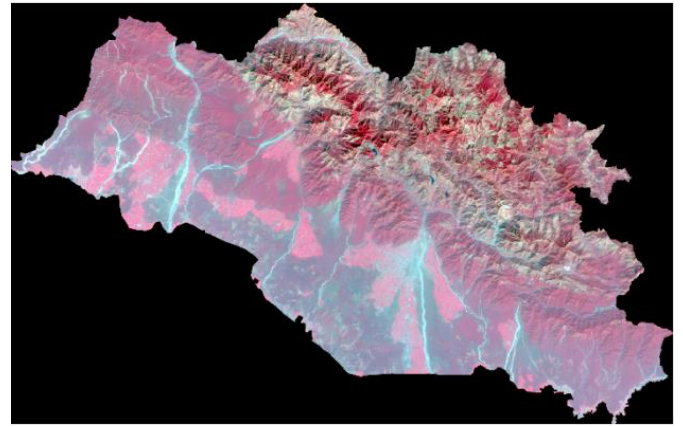

FCC Image for February

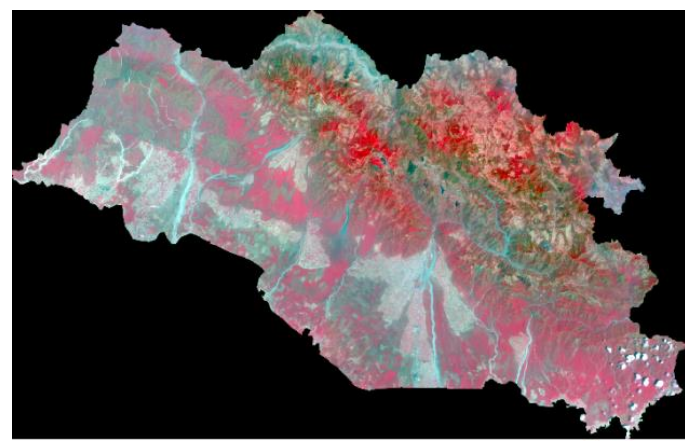

FCC Image for May

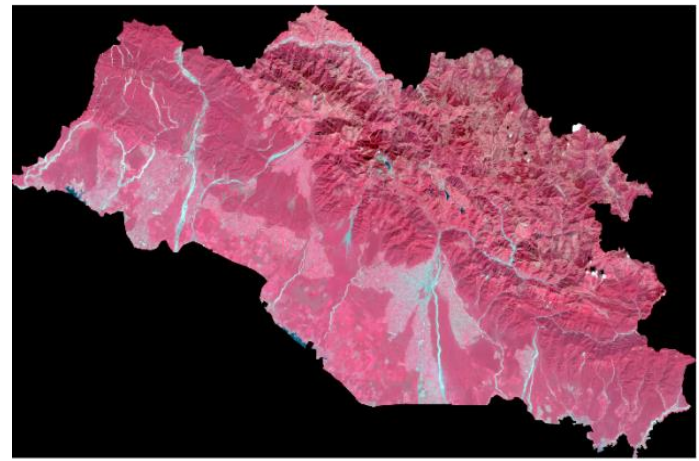

FCC Image for October

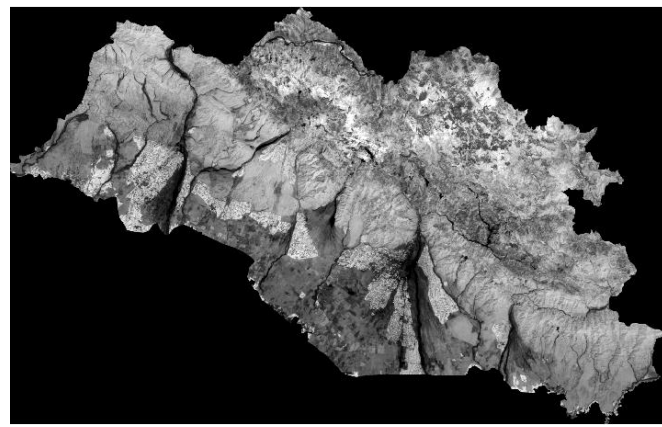

NDVI Image of February

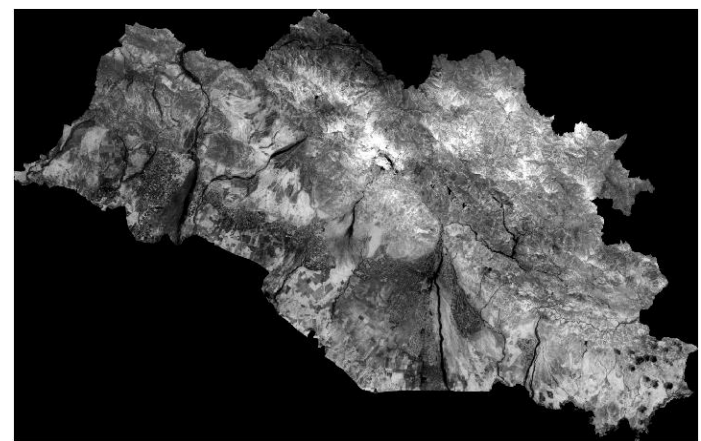

NDVI image of May

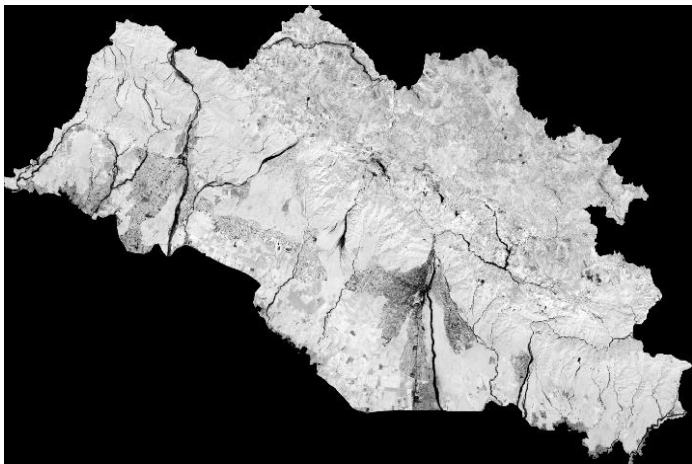

NDVI image of October 
The measured linear scattering intensities whether from co-polarization or from cross-polarization are utilized by this index. The index values range between 0 to1, which increases with the vegetation cover. Although there is a need to revise the Radar Index Vegetation index as with the case of any forest cover it records not only the information coming from the vegetation scattering but also the scattering from the soil.

Table 5 reports a summary of the lowest and highest value of NDVI in different seasons. October represents the highest value of NDVI among the three seasons. The value in February and May are almost similar, and there is a very small difference in the NDVI values. The reason could be different types of disturbances which in turn affects the forest cover.

Table 5: NDVI values of different seasons

\begin{tabular}{|c|c|c|c|}
\hline NDVI/ Months & February & May & October \\
\hline Minimum (Low) & -0.186897 & -0.10468 & -0.26752 \\
\hline Maximum (High) & 0.758754 & 0.739651 & 0.839569 \\
\hline
\end{tabular}

\section{Random Points Generation}

For correlating the values of the NDVI and the RVI data some random points were generated on the forested areas and their values were extracted at the points. It was done for all the images for extracting the NDVI and RVI values. Sentinel 2A images were used for calculating the NDVI values. The three NDVI images of February, May and October exhibited different NDVI values.

\section{Fig. 16: Random points overlaid on all images}

Sentinel 2A/B Image

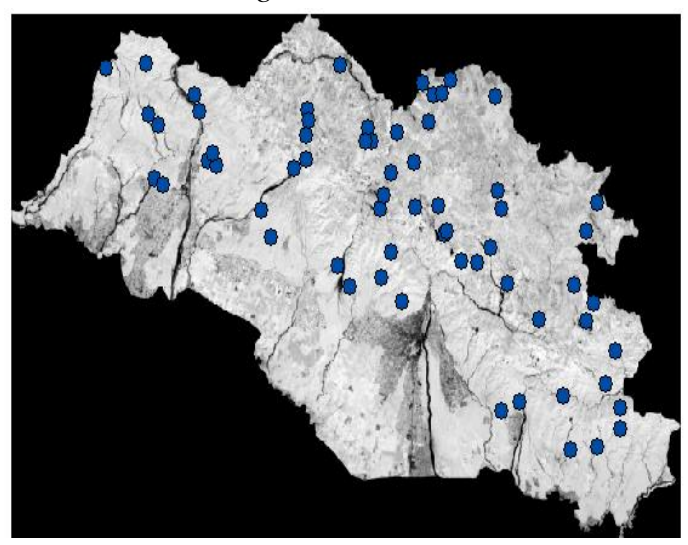

Sentinel 1A/B Image

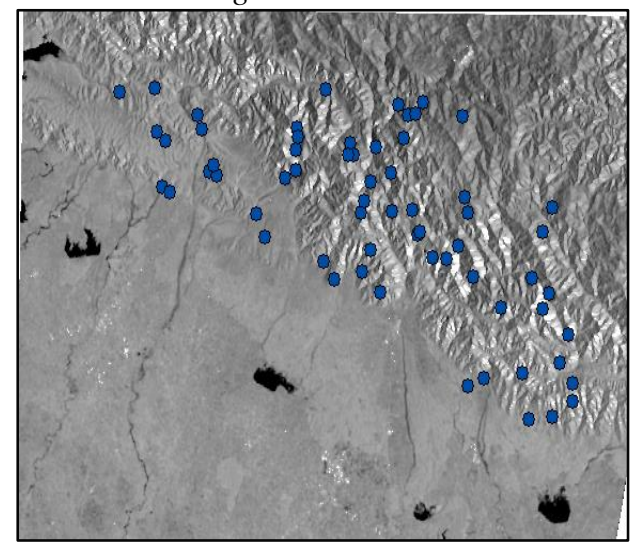




\section{Google Earth Image}

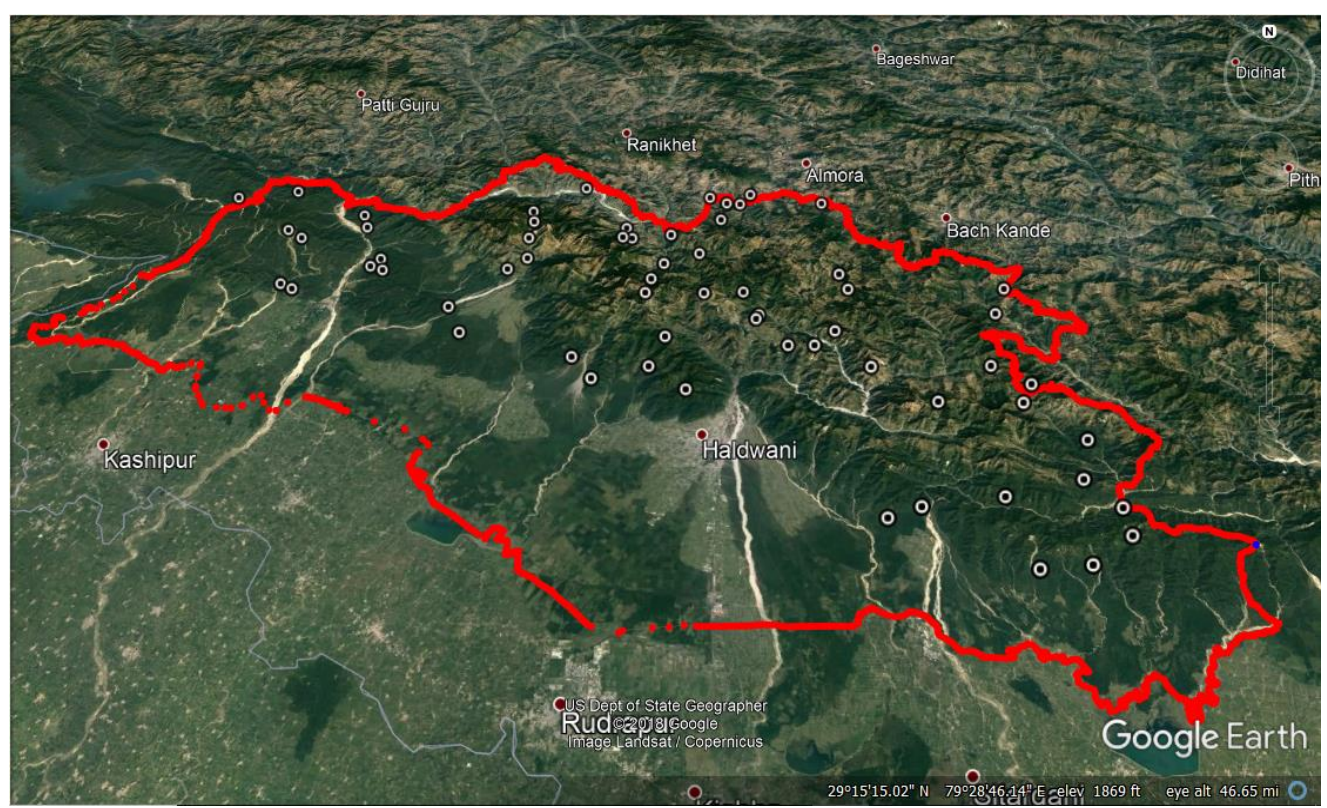




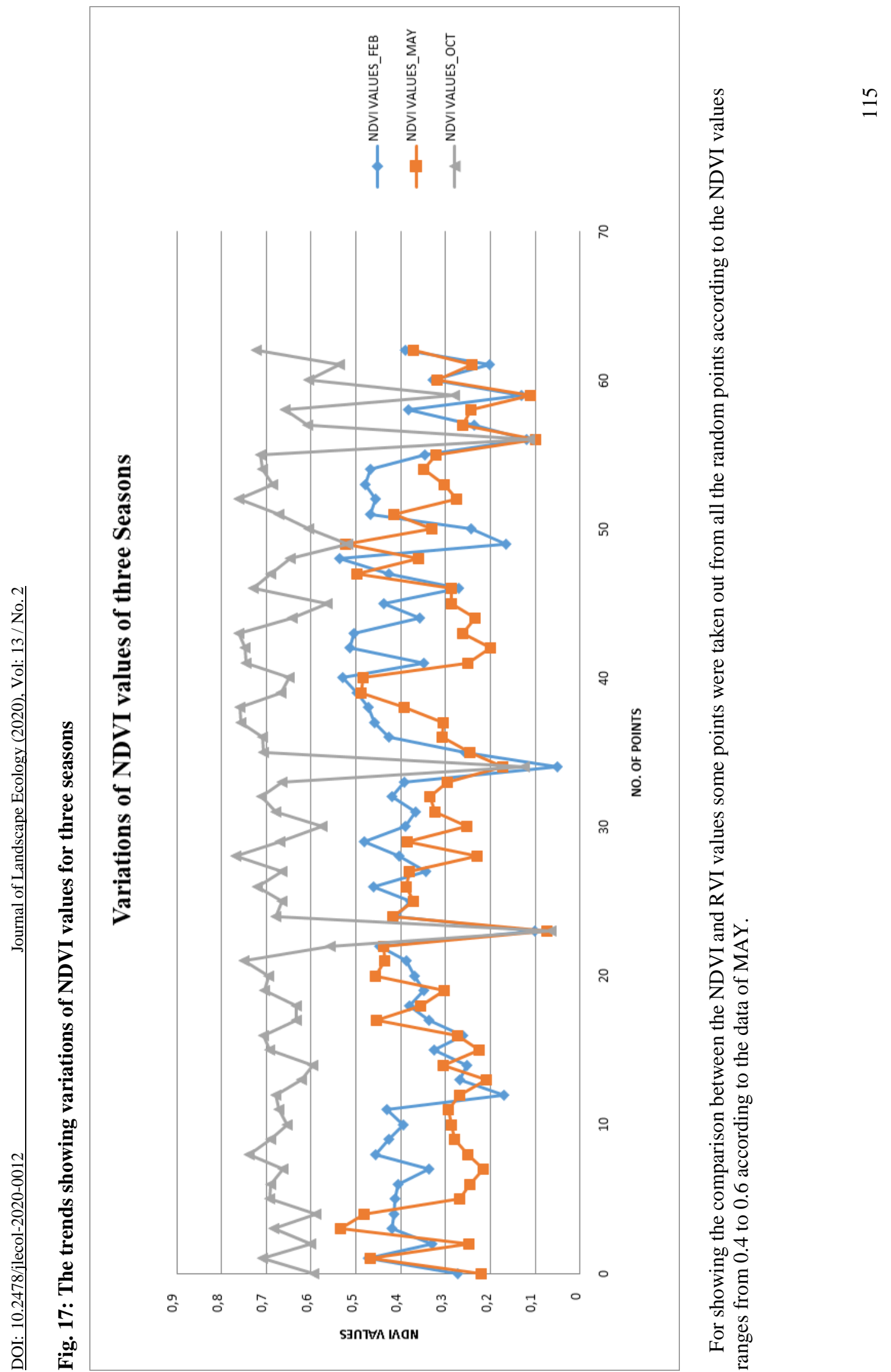




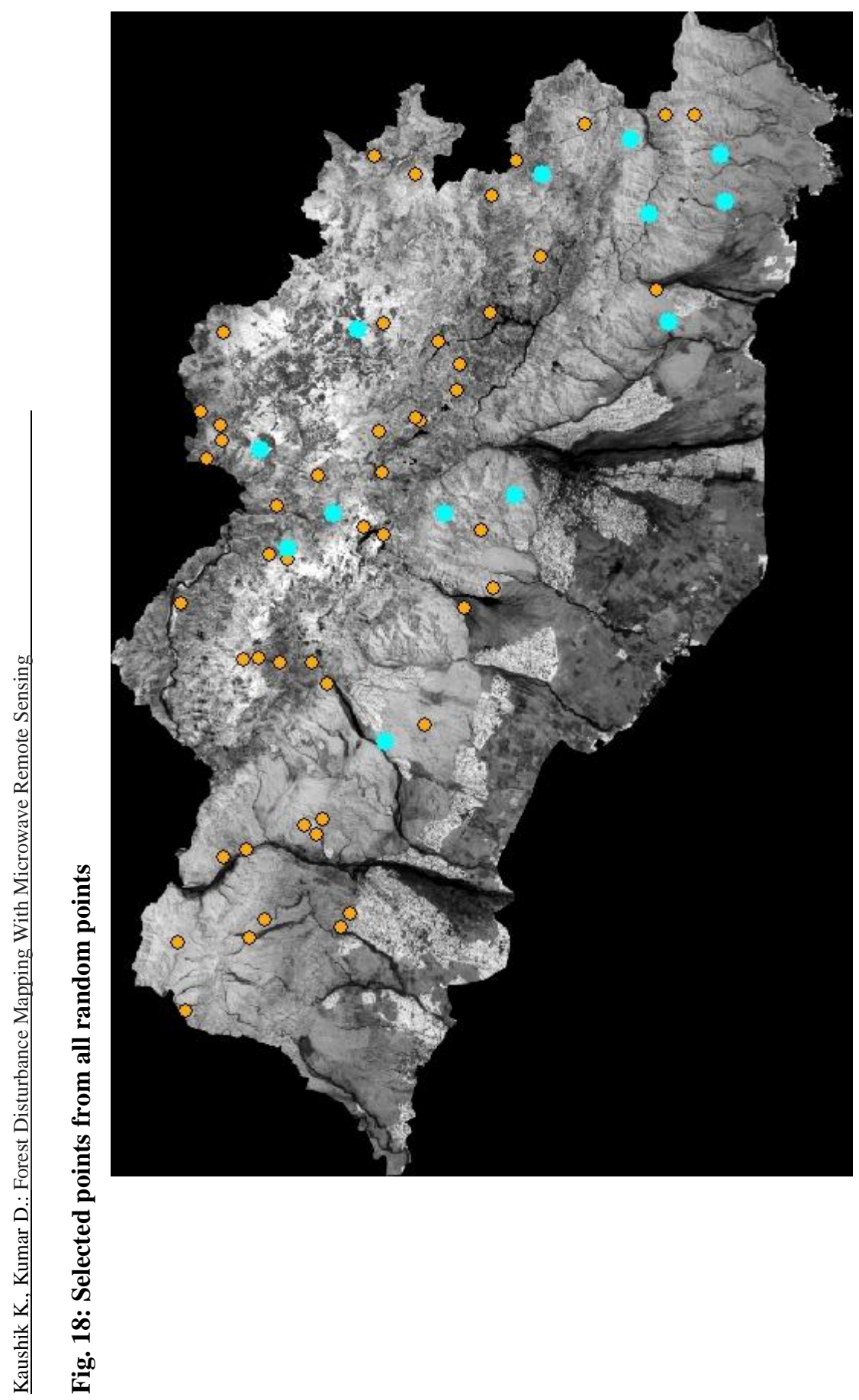




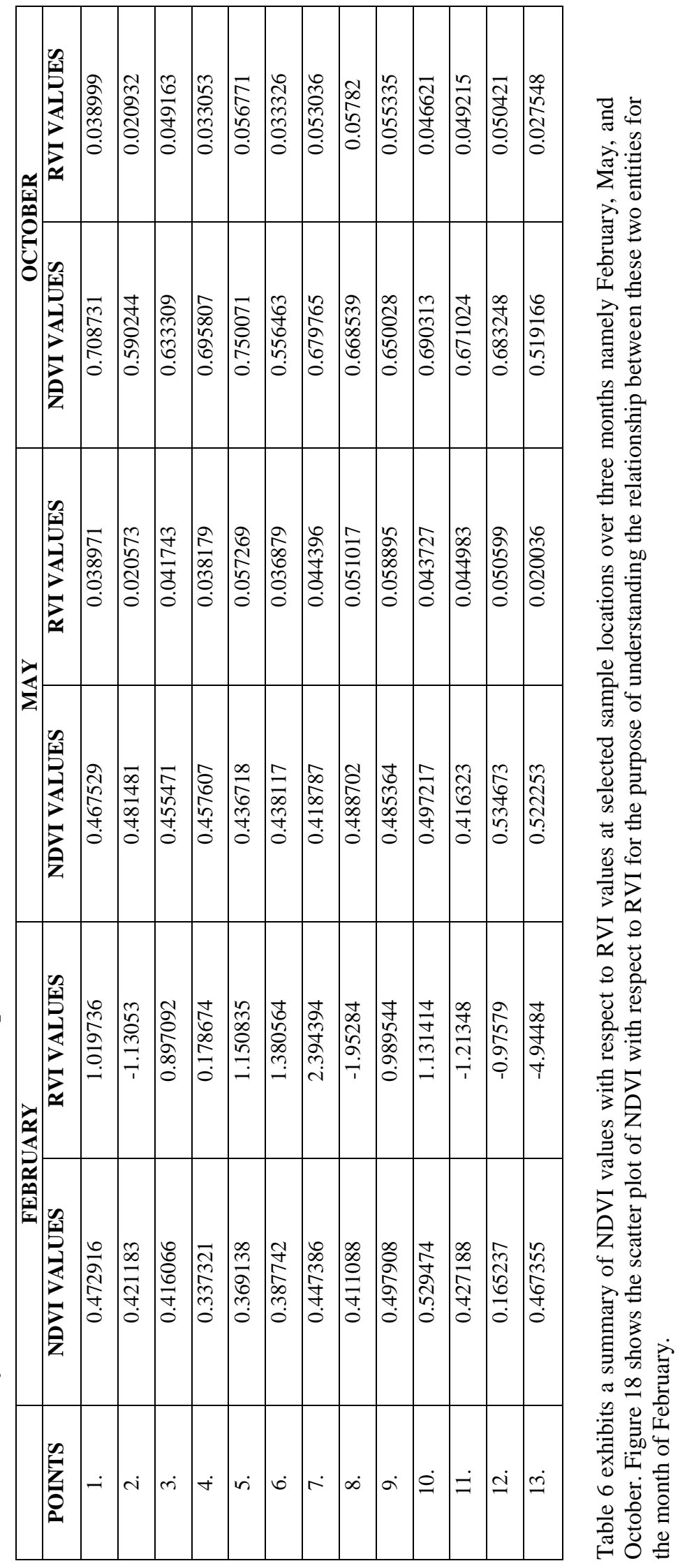




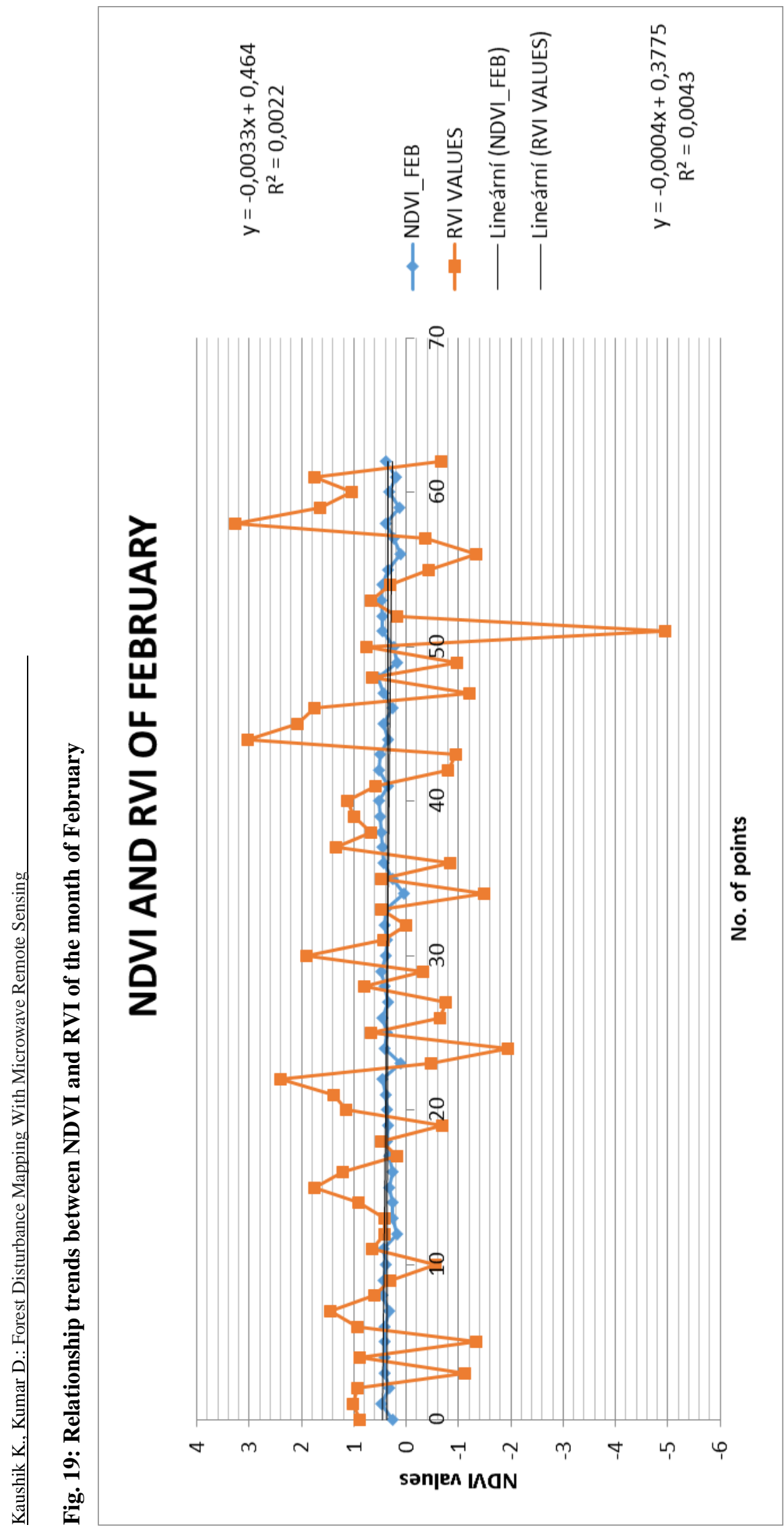

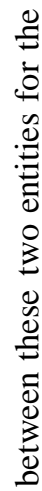

.

$\stackrel{9}{5}$

:

4

8

ํㅡㄹ

듬

ᄒ

2

웅

迆

ڤ્ટ

壱

字

4

음

氖

$\stackrel{乛}{ \pm}$

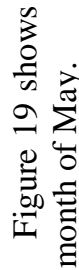




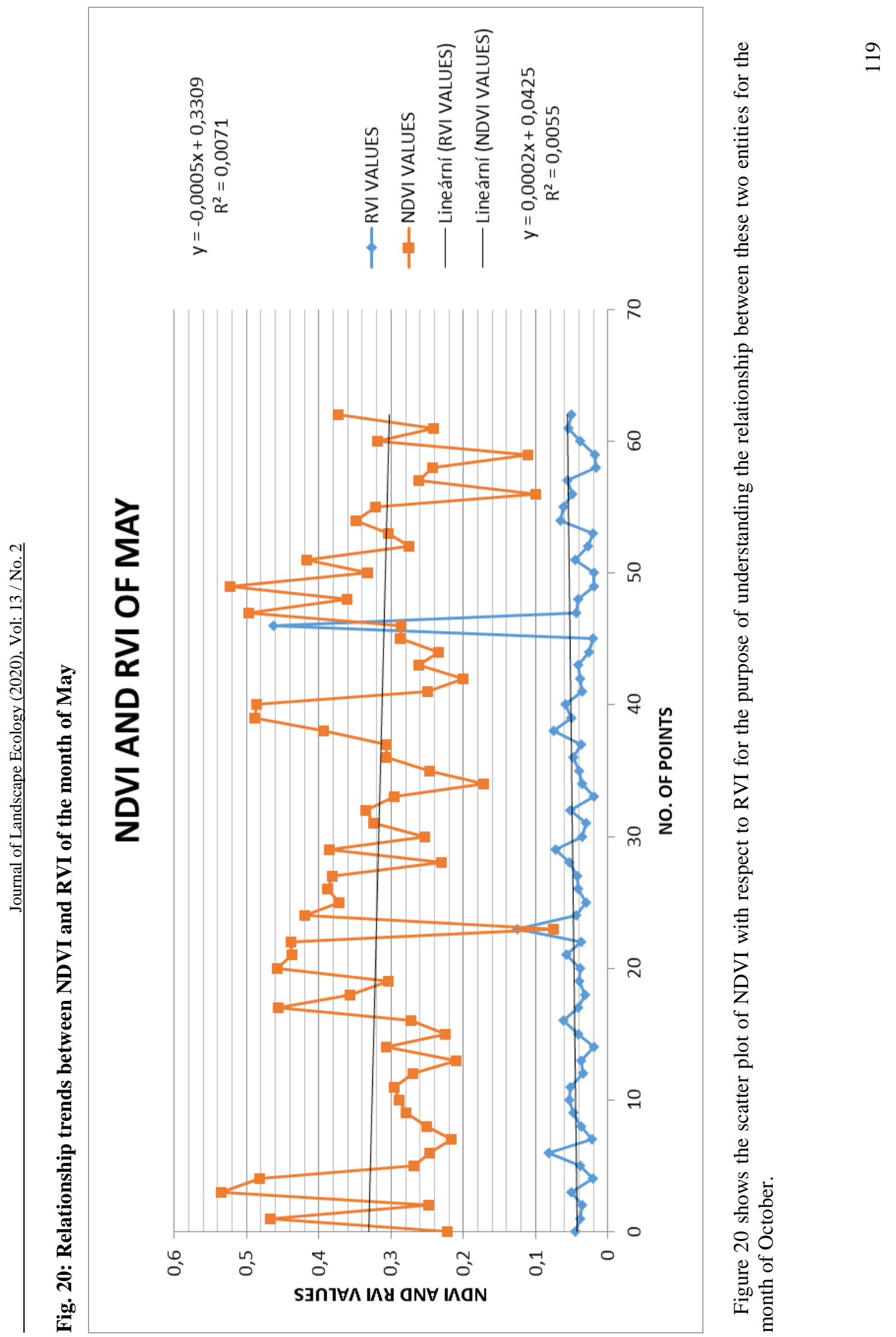




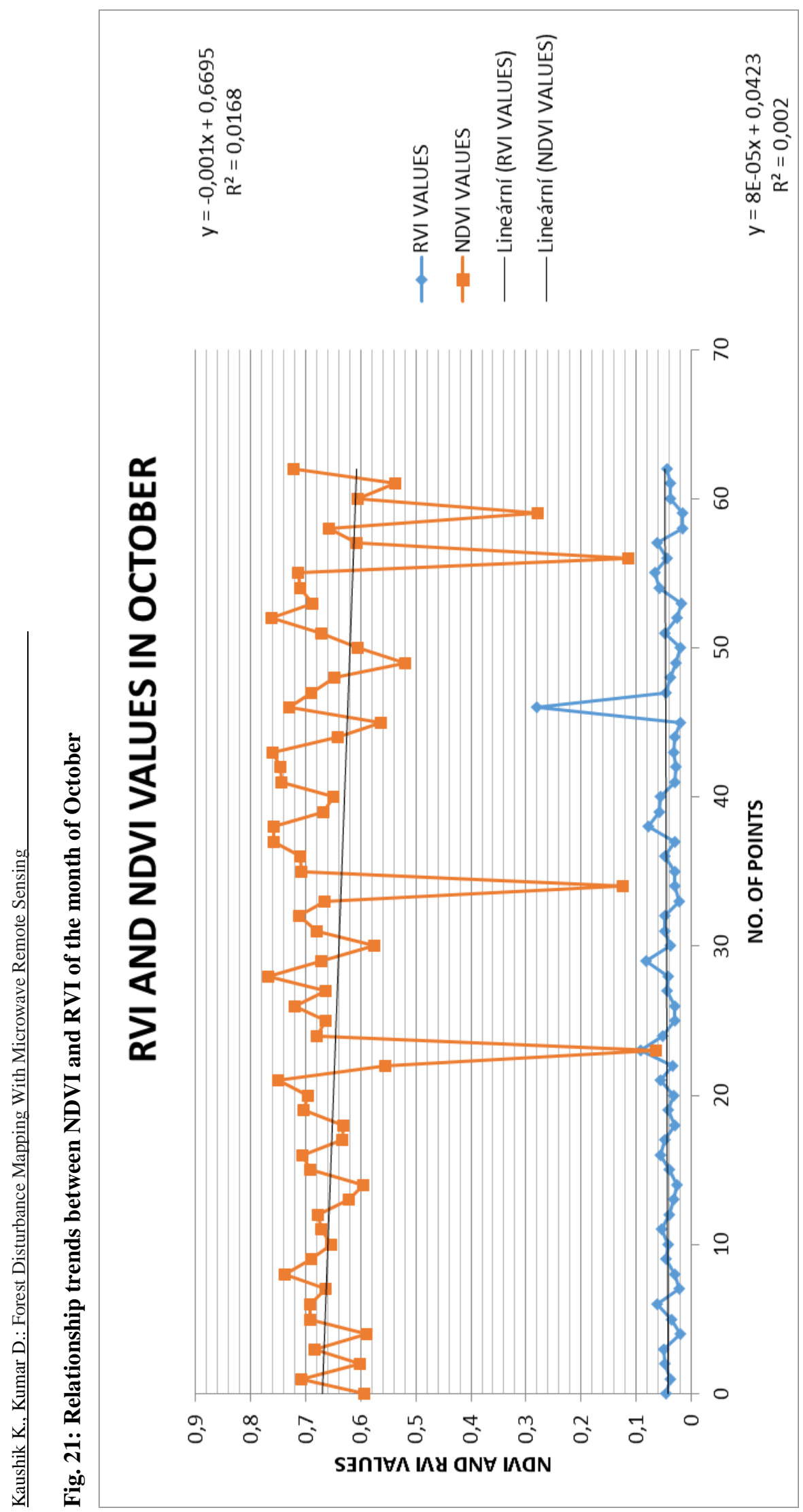


Table 6: Parametrization of NDVI values

\begin{tabular}{|l|l|l|}
\hline \multicolumn{1}{|c|}{ FEBRUARY } & \multicolumn{1}{|c|}{ MAY } & \multicolumn{1}{|c|}{ OCTOBER } \\
\hline $\begin{array}{l}\mathrm{y}=-0.0004 \mathrm{x}+0.3775 \\
\mathrm{R}^{2}=0.0043\end{array}$ & $\begin{array}{l}\mathrm{y}=-0.0005 \mathrm{x}+0.3309 \\
\mathrm{R}^{2}=0.0071\end{array}$ & $\begin{array}{l}\mathrm{y}=-0.001 \mathrm{x}+0.6695 \\
\mathrm{R}^{2}=0.0168\end{array}$ \\
\hline
\end{tabular}

Table 6 reports the linear relationship of NDVI over three months. The formula for calculating the radar vegetation index is:

$$
\mathrm{RVI}=\frac{8 \cdot \sigma_{0} \mathrm{HV}}{\sigma_{0} \mathrm{HH}+2 \cdot \sigma_{0} \mathrm{HV}+\sigma_{0} \mathrm{VV}}
$$

But here we have used the modified formula because of the non- availability of quad-pol data. As the data which was used was dual-pol with the VV and VH polarization:

$$
\mathrm{RVI}=\frac{4 \cdot \sigma_{0} \mathrm{HV}}{\sigma_{0} \mathrm{HH}+\sigma_{0} \mathrm{HV}}
$$

After calculating and plotting the NDVI and RVI values it is visible that the values. During February are highly fluctuating as there are many values which are below 0 whereas the same point in the other two images are above 0 and have positive values. For May, the values are all above 0 and there is no negative value for any point. The graph for October shows a reverse relationship between the NDVI and the RVI as where the NDVI value is low the RVI value is higher and vice versa.

The RVI value for May and October is almost same with a slight difference but the values of NDVI for the same points show variation, as for some points it is same but the majority of values in May is varying between 0.2 to 0.5 but the same points in October are showing high NDVI values ranging between 0.6 to 0.7 . The difference between the two can be a result of soil moisture in the area which is captured in the radar imagery. The fluctuating values in February can be a result of any type of disturbance in the area. The fire cases in Nainital district start to circle in the area in the start of February as the district has a large Forest cover of a dry deciduous type which is vulnerable to forest fires. Forest fires have been a major concern in Nainital district, $90 \%$ of the factors responsible for fires are anthropogenic whether they are intentional or accidental. According to the reports, The Himalayan forests have been burning regularly during the last few summers when there is no rain for months and the forest become littered with dry leaves and twinges which could burst into flames with the slightest of spark. The cases of forest fires are increasing in the district as almost all of them are intentional and are done by the mafias for wood smuggling.

According to a report of Times of India, 168.28 hectares of forest have been reduced to ashes in Nainital in 170 cases of wildfire incidents. Fires can be monitored and analyzed in a timely and cost-effective manner by using remote sensing technology in combination with GIS.

\section{Comparative study of NDVI and Backscatter Values}

Microwave remote sensing radar records the backscattered values. Every feature exhibits different backscattered values. If the $\mathrm{dB}$ value is more than 0 or positive it can infer to settlement or manmade feature, the vale ranging from $0 \mathrm{~dB}$ to $-10 \mathrm{~dB}$ approximately represents forest cover, -10 to -20 is an indicator of the vegetated area and the value more 
than -20 represents a water body. For showing the scatter plot of NDVI and the backscatter values the same points have been used as above. The graph below represents the NDVI values and the different backscattered values from $\mathrm{VV}$ and $\mathrm{VH}$ polarization. The backscattered values of VV and VH polarizations were also calculated which represented that the VV polarization which is vertically transmitted and vertically received is sensitive to the forest cover. 

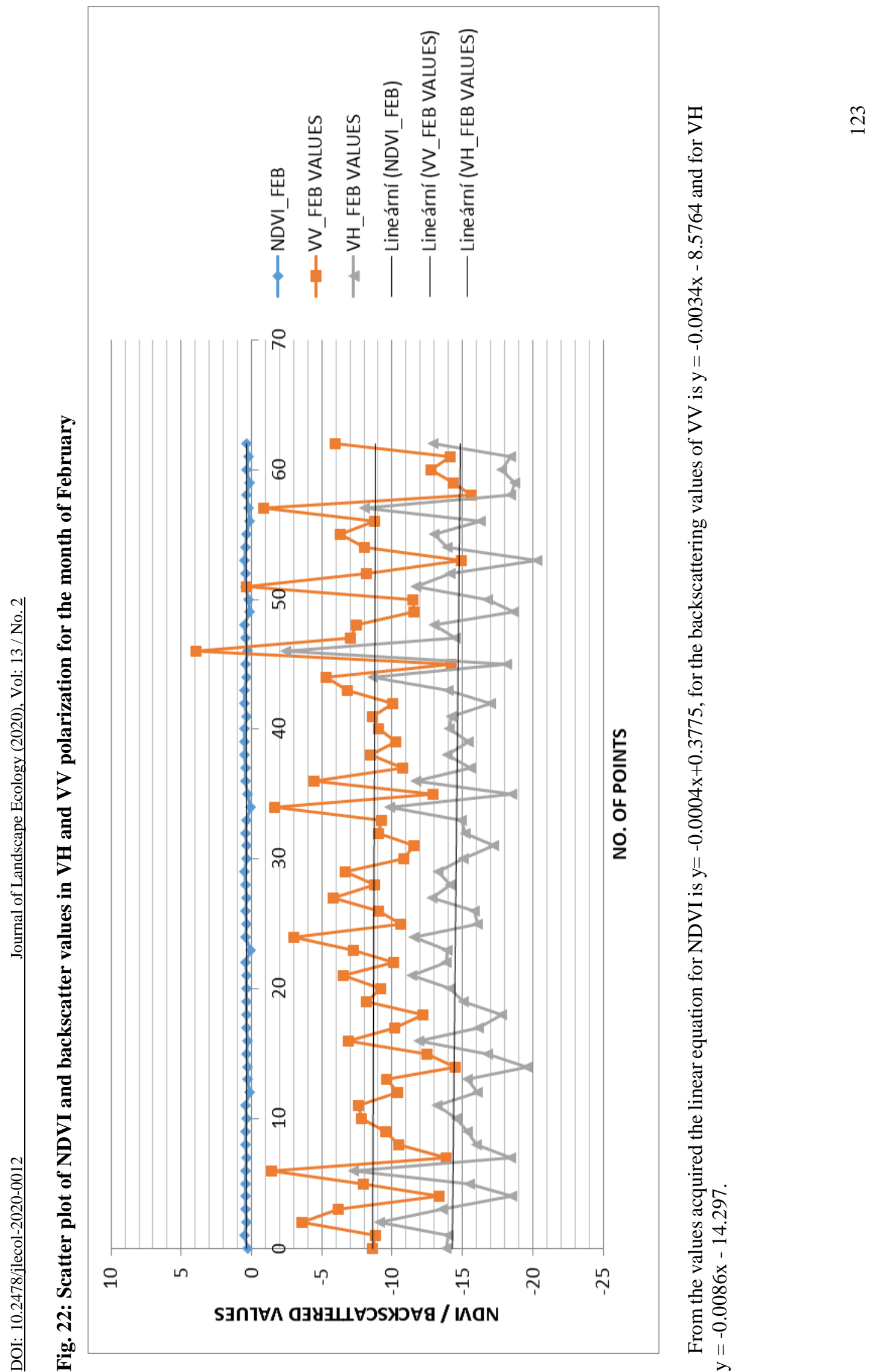

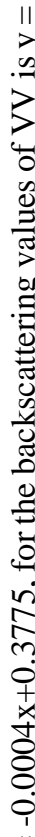

II

斑

ప્డ

.

․․․

छั

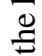

ఫृ

웡

过

等

$\stackrel{2}{\doteq}$

룽

논 11 


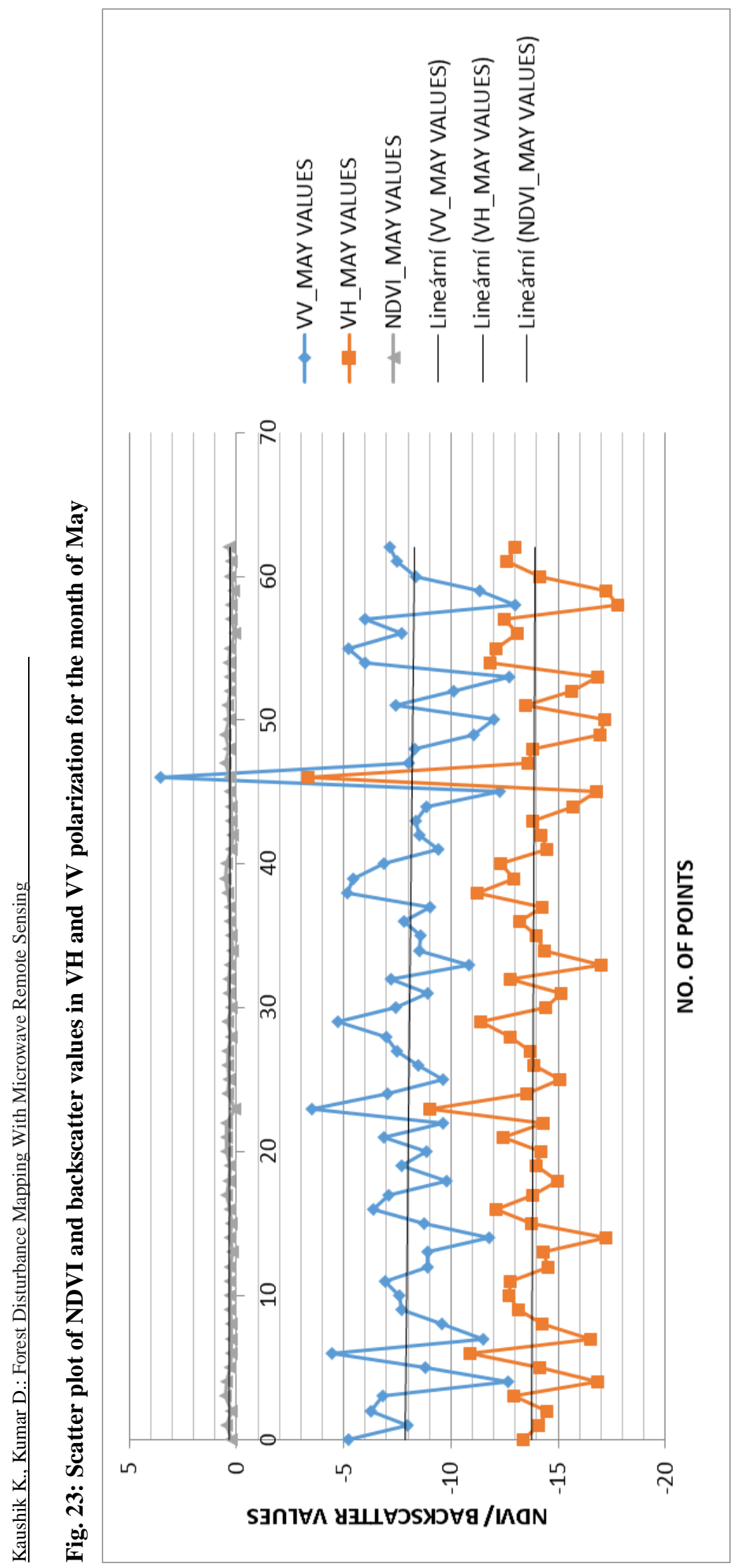

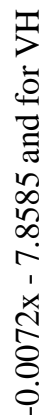

$\sum_{\substack{2 \\ 2}}^{11}$

舟

Е

造

Е

흐

ô

?

$+$

๖̊ํㅇ

ఠ

II

是

ธั0

음

릉

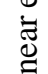

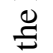

D্

突

क

元

ฮ ฮิ

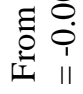




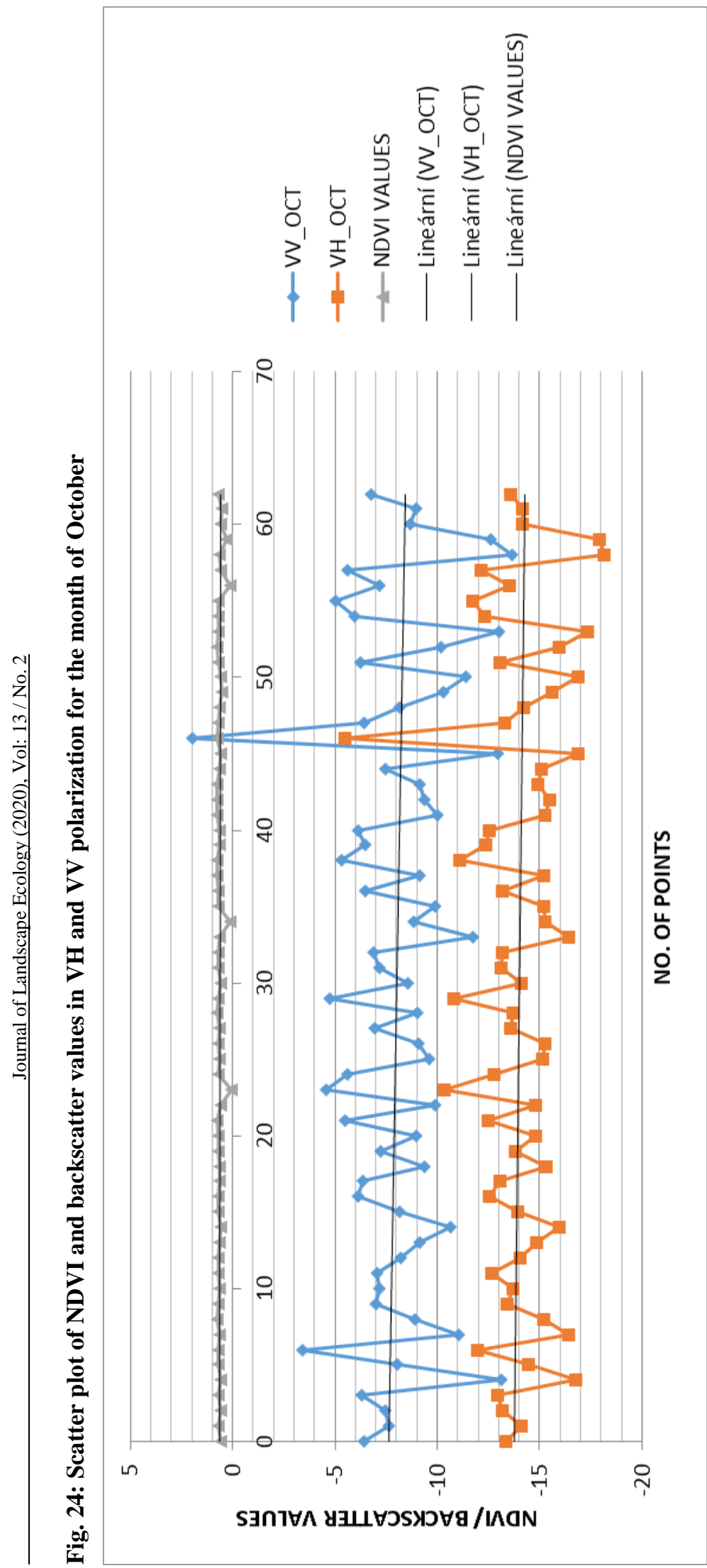

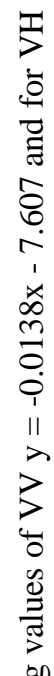

I

$\Xi$

\%

记

Ð

。

2
0
0
0
+
+
0
0
0

II

.

2

ᄒำ

흠

పี



Ðூ

ฮู슷

Ð

尔

$\stackrel{\infty}{\infty}$

융

章 II 


\section{CONCLUSION}

The use of microwave remote sensing in dual-polarization C-band datasets has not been explored too much to study and analyze the forest disturbances. There is huge potential of utilizing SAR data for mapping forest disturbances due to the availability of Cloud free datasets with slight penetration capability. The current work also aims towards the processing of the SAR datasets for application the field of forestry. A base layer was added to analyze the forest cover of the district and values of the random points were extracted.

The backscattered sigma nought values were also analyzed for identifying the difference between the two polarizations which are used in the radar data as it is dual-pol data with the combination of VV and $\mathrm{VH}$ (Vertically transmit and vertically received and vertically transmitted and horizontally received) polarizations. NDVI (Normalized differential vegetation index) and RVI (Radar vegetation index) were calculated to find the correlation between these indices in mapping the disturbance in the area. NDVI was derived through the help of ERDAS Imagine software and the RVI was estimated through SNAP software. For forest disturbance mapping both the optical and microwave data were used to derive NDVI and RVI values and to visualize their relationship for monitoring the disturbances in the forest area but due to the exposure of soil moisture in the radar vegetation index, it doesn't correlate with the NDVI data and illustrates the inverse correlation.

\section{REFERENCES}

Achard, F., Eva, H. D., Stibig, H. J., Mayaux, P., Gallego, J., Richards, T., \& Malingreau, J. P. (2002). Determination of deforestation rates of the world's humid tropical forests. Science. https://doi.org/10.1126/science.1070656

Bassuk, N. L., Universite, A. B., Jean, M., Universite, C., Theoretical, L., Politics, U., ... Bibliography, A. A. (2015). On using landscape metrics for landscape similarity search. Landscape and Urban Planning, 117(1), 1-12. https://doi.org/10.1038/srep11160

Bouvet, A., Mermoz, S., Ballère, M., Koleck, T., \& Le Toan, T. (2018). Use of the SAR shadowing effect for deforestation detection with Sentinel-1 time series. Remote Sensing. https://doi.org/10.3390/rs10081250

Carmenta, R., Parry, L., Blackburn, A., Vermeylen, S., \& Barlow, J. (2011). Understanding Human-Fire interactions in tropical forest regions: A case for interdisciplinary research across the Natural and Social Sciences. Ecology and Society. https://doi.org/10.5751/ES-03950-160153

Chauhan, J. S., Gautam, A. S., \& Negi, R. S. (2018). Natural and Anthropogenic Impacts on Forest Structure: A Case Study of Uttarakhand State. The Open Ecology Journal. https://doi.org/10.2174/1874213001811010038

Chu, T., \& Guo, X. (2013). Remote sensing techniques in monitoring post-fire effects and patterns of forest recovery in boreal forest regions: A review. Remote Sensing. https://doi.org/10.3390/rs6010470

Dimov, D., Kuhn, J., \& Conrad, C. (2016). ASSESSMENT OF CROPPING SYSTEM DIVERSITY IN THE FERGANA VALLEY THROUGH IMAGE FUSION OF LANDSAT 8 AND SENTINEL-1. III(July), 12-19. https://doi.org/10.5194/isprsannals-III-7-173-2016

Dovì, V. G., Friedler, F., Huisingh, D., \& Klemeš, J. J. (2009). Cleaner energy for sustainable future. Journal of Cleaner Production. https://doi.org/10.1016/j.jclepro.2009.02.001

Food and Agriculture Organisation (FAO). (2010). Global Forest Resources Assessment 
2010 - Main report. Food and Agriculture Organization: Rome, Italy. In FAO Forestry Paper 163.

Ghosh, U., \& Circle, N. (n.d.). Agroforestry : Key for achieving one third area under forest and tree cover. $1-11$.

Kimball, J. S., McDonald, K. C., Frolking, S., \& Running, S. W. (2004). Radar remote sensing of the spring thaw transition across a boreal landscape. Remote Sensing of Environment, 89(2), 163-175.

Le Toan, T., Beaudoin, A., Riom, J., \& Guyon, D. (1992). Relating Forest Biomass to SAR Data. IEEE Transactions on Geoscience and Remote Sensing. https://doi.org/10.1109/36.134089

Margules, C. R., \& Pressey, R. L. (2000). Systematic conservation planning. Nature, 405(6783), 243-253.

Mbow, C., Smith, P., Skole, D., Duguma, L., \& Bustamante, M. (2014). Achieving mitigation and adaptation to climate change through sustainable agroforestry practices in africa. Current Opinion in Environmental Sustainability, 6(1), 8-14. https://doi.org/10.1016/j.cosust.2013.09.002

Mermoz, S., \& Le Toan, T. (2016). Forest disturbances and regrowth assessment using ALOS PALSAR data from 2007 to 2010 in Vietnam, Cambodia and Lao PDR. Remote Sensing. https://doi.org/10.3390/rs8030217

Mermoz, S., Réjou-Méchain, M., Villard, L., Le Toan, T., Rossi, V., \& Gourlet-Fleury, S. (2015). Decrease of L-band SAR backscatter with biomass of dense forests. Remote Sensing of Environment. https://doi.org/10.1016/j.rse.2014.12.019

Nutini, F., Boschetti, M., Candiani, G., \& Bocchi, S. (2014). Evaporative Fraction as an Indicator of Moisture Condition and Water Stress Status in Semi-Arid Rangeland Ecosystems. Remote Sensing, 6, 6300-6323. https://doi.org/10.3390/rs6076300

Reiche, J., Lucas, R., Mitchell, A. L., Verbesselt, J., Hoekman, D. H., Haarpaintner, J., ... Herold, M. (2016). Combining satellite data for better tropical forest monitoring. Nature Climate Change. https://doi.org/10.1038/nclimate2919

Sailor, D. J., \& Dietsch, N. (2007). The urban heat island Mitigation Impact Screening Tool (MIST). Environmental Modelling \& Software, 22(10), 1529-1541. https://doi.org/10.1016/j.envsoft.2006.11.005

Shahabi, H., \& Hashim, M. (2015). Landslide susceptibility mapping using GIS-based statistical models and Remote sensing data in tropical environment. Scientific Reports, 5, 115. https://doi.org/10.1038/srep09899

Shareef, M. A., Khenchaf, A., \& Toumi, A. (2016). Integration of Passive and Active Microwave Remote Sensing to Estimate Water Quality Parameters.

Shastri, B. P., Haldar, D., \& Mohan, S. (2015). Temporal Monitoring of SAR Polarimetric Parameters and Scattering Mechanism for Major Kharif Crops and Surrounding Land Use. IJSRSET, 1(4), 416-424.

Singh, L., Mutanga, O., Mafongoya, P., \& Peerbhay, K. Y. (2017). Multispectral mapping of key grassland nutrients in KwaZulu-Natal, South Africa. Journal of Spatial Science, 8596, 118. https://doi.org/10.1080/14498596.2017.1341352

Smith, A. (2010). Image segmentation scale parameter optimization and land cover classification using the random forest algorithm. Journal of Spatial Science, 55(1), 69-79. https://doi.org/10.1080/14498596.2010.487851 
Stibig, H. J., Achard, F., Carboni, S., Raši, R., \& Miettinen, J. (2014). Change in tropical forest cover of Southeast Asia from 1990 to 2010. Biogeosciences. https://doi.org/10.5194/bg-11-247-2014

Verbesselt, J., Hyndman, R., Newnham, G., \& Culvenor, D. (2010). Detecting trend and seasonal changes in satellite image time series. Remote Sensing of Environment, 114(1), 106-115.

Wolfgang, W. (2016). FOREST AREA DERIVATION FROM SENTINEL-1 DATA. III(July), 227-233. https://doi.org/10.5194/isprsannals-III-7-227-2016

Wu, W., \& Pauw, E. De. (2008). A Simple Algorithm to Identify Irrigated Croplands by Remote Sensing. (2007), 2006-2008.

1. (Achard et al., 2002; Bouvet, Mermoz, Ballère, Koleck, \& Le Toan, 2018; Carmenta, Parry, Blackburn, Vermeylen, \& Barlow, 2011; Chauhan, Gautam, \& Negi, 2018; Chu \& Guo, 2013; Food and Agriculture Organisation (FAO), 2010; Le Toan, Beaudoin, Riom, \& Guyon, 1992; Mermoz \& Le Toan, 2016; Mermoz et al., 2015; Reiche et al., 2016; Stibig, Achard, Carboni, Raši, \& Miettinen, 2014; Wolfgang, 2016)

2. http://cgwb.gov.in/District_Profile/Uttarakhand/Nainital.pdf

3. https://www.intechopen.com/books/land-applications-of-radar-remote-sensing/larg e-scale-mapping-of-forests-and-land-cover-with-synthetic-aperture-radar-data

4. $\quad$ SAR preprocessing documentation by Thomas weib, April 19' 2018.

5. https://www.mdpi.com/2072-4292/6/1/470/htm\#b1-remotesensing-06-00470 